\title{
OsINV3 and Its Homolog, OsINV2, Control Grain Size in Rice
}

\author{
Xiaoshu Deng ${ }^{1,2,+}$, Xiaohang Han ${ }^{1,2,+}$, Shicong Yu ${ }^{1,2}$, Zhijian Liu ${ }^{1,2}$, Daiming Guo ${ }^{1,2}$, \\ Yao He ${ }^{1,2}$, Wenyi Li ${ }^{1,2}$, Yu Tao ${ }^{1,2}$, Chaowei Sun ${ }^{1,2}$, Peizhou Xu ${ }^{1,2}$, Yongxiang Liao ${ }^{1,2}$, \\ Xiaoqiong Chen ${ }^{1,2}$, Hongyu Zhang ${ }^{1,2, *}$ and Xianjun $\mathrm{Wu}^{1,2, *}$ \\ 1 Rice Research Institute, Sichuan Agricultural University, Chengdu 611130, China; \\ dengxss520@163.com (X.D.); hanxhasd@163.com (X.H.); shicongyu@aliyun.com (S.Y.); \\ 18302879527@163.com (Z.L.); daiming_guo@outlook.com (D.G.); heyao2017@gmail.com (Y.H.); \\ liwenyi0921@163.com (W.L.); 18408211896@163.com (Y.T.); zavierstayhere@outlook.com (C.S.); \\ xpzhxj@163.com (P.X.); liaoyongxiang123@163.com (Y.L.); xiaochenq777@126.com (X.C.) \\ 2 Key Laboratory of Southwest Crop Genetic Resources and Genetic Improvement, Ministry of Education, \\ Chengdu 611130, China \\ * Correspondence: zhanghysd@163.com (H.Z.); wuxj@sicau.edu.cn (X.W.) \\ + These authors contribute equally to this work.
}

Received: 19 February 2020; Accepted: 21 March 2020; Published: 23 March 2020

check for updates

\begin{abstract}
Vacuolar invertase is involved in sugar metabolism and plays a crucial role in plant growth and development, thus regulating seed size. However, information linking vacuolar invertase and seed size in rice is limited. Here we characterized a small grain mutant $s g 2$ (grain size on chromosome 2) that showed a reduced in grain size and 1000-grain weight compared to the wild type. Map-based cloning and genetic complementation showed that OsINV3 is responsible for the observed phenotype. Loss-of-function of OsINV3 resulted in grains of smaller size when compared to the wild type, while overexpression showed increased grain size. We also obtained a T-DNA insertion mutant of OsINV2, which is a homolog of OsINV3 and generated double knockout $(K O)$ mutants of OsINV2 and OsINV3 using CRISPR/Cas9. Genetic data showed that OsINV2, that has no effect on grain size by itself, reduces grain length and width in the absence of OsINV3. Altered sugar content with increased sucrose and decreased hexose levels, as well as changes vacuolar invertase activities and starch constitution in $I N V 3^{K O}, I N V 2^{K O}, I N V 3^{K O} I N V 2^{K O}$ mutants indicate that $O s I N V 2$ and OsINV3 affect sucrose metabolism in sink organs. In summary, we identified OsINV3 as a positive regulator of grain size in rice, and while OsINV2 has no function on grain size by itself. In the absence of OsINV3, it is possible to detect a role of OsINV2 in the regulation of grain size. Both OsINV3 and OsINV2 are involved in sucrose metabolism, and thus regulate grain size. Our findings increase our understanding of the role of OsINV3 and its homolog, OsINV2, in grain size development and also suggest a potential strategy to improve grain yield in rice.
\end{abstract}

Keywords: rice (Oryza sativa); grain size; OsINV3; OsINV2; sucrose metabolism

\section{Introduction}

The Rice is an important cereal crop that feeds majority of the global population. There is an urgent need to increase the yield of rice to support the rapid growth of global population. Grain size is one of the most important factors that determines grain yield in rice. Thus, investigation of grain size-associated genes and elucidation of their functional mechanisms have great significance for further improvement of rice yield [1]. So far, several genes related to grain size have been documented. These genes are involved in regulating multiple signaling pathways [2-6], including the ubiquitination-mediated 
proteasomal degradation pathway, the mitogen-activated protein kinase (MAPK) signaling pathway, G-protein signaling, phytohormone signaling pathway and transcriptional regulatory factors. For example, the genes involved in ubiquitination-mediated proteasomal degradation pathway include GW2 [7], HGW [8], TUD1 [9], and WTG1 [10]. The genes involved in the MAPK signaling pathway include OsMKK4 [11], OsMAPK6 [12], OsMKP1/GSN1 [13], and OsMKKK10 [14,15]. The OsMKKK10-OsMKK4-OsMAPK6 signaling pathway positively regulates grain size and weight in rice. Rice encodes a $G \alpha$, a $G \beta$, and five $G \gamma$ proteins [16]. The $G \beta$ protein is essential for plant survival and growth, $G \alpha$ provides a foundation for grain size expansion, while the $G \gamma$ proteins function as antagonists to regulate grain size [17]. The phytohormone pathway genes include OsSGL [18,19], GAD1 [20], SRS3 [21], and GDD1 [22]. Another important set of signaling pathway genes controlling grain size are transcriptional regulatory factors, which play a crucial role in rice development, especially during the course of grain growth. For example, OsPIL15 [23], a helix-loop-helix transcription factor, regulates grain size by directly targeting a purine permease gene OsPUP7. Recently, GL6, a new QTL, that encodes a plant-specific PLATZ (plant AT-rich sequence- and zinc-binding) transcription factor affecting grain length and spikelet number was identified [24]. However, the molecular roles of some regulators in grain size control are yet unclear or controversial [6]. The genetic relationships among different regulators and the molecular interactions amongst different signaling pathways are largely unknown. Invertase (EC 3.2.1.26) is a key enzyme in carbohydrate metabolism that irreversibly hydrolyzes sucrose into glucose and fructose, both of which are basic energy sources, and act as signaling molecules for plant growth, crop yield and stress responses [25-28]. Based on subcellular location, invertases are classified into cell wall invertases (CWINs), vacuolar invertases (VINs) and cytoplasmic invertases (CINs) [29]. CWINs and VINs have optimal activity at an acidic $\mathrm{pH}$ (3.5-5.5), while CINs function optimally in an alkaline or neutral $\mathrm{pH}(6.8-8.0)$ [29]. Little is known about the function and regulation of CINs. CWINs play a key role in assimilate partitioning, thus regulating grain weight in crops [30,31]. VINs regulate cell expansion, osmotic pressure, sugar signals, sucrose accumulation, and sucrose concentration, especially during the expansion phases of sink organs [32]. VIN belongs to $\beta$-fructofuranosidases, a group of $N$-glycosylated proteins that contain a $\beta$-fructosidase motif (NDPN) and a cysteine catalytic domain (WECVD), both of which are essential for the catalytic activity of VIN [28]. In Arabidopsis, a gene encoding vacuolar invertase was reported to control the lengths of roots and hypocotyls, especially in the elongating zones of roots [33]. Vacuolar invertase activity was detected in the cell elongation zone of the seminal root in maize seedlings [34]. It has also been speculated that VIN contributes to fiber cell elongation in cotton [35]. In potato, VIN is the key determinant in reducing sugar accumulation during cold-induced sweetening [36,37]. VIN silencing was found to significantly reduce cold-induced sweetening in stored potato tubers, thus addressing a long-standing quality problem in French fries [38]. In rice, two VIN isogenes, OsINV2 and OsINV3, have been identified [39]. OsINV3 plays a role in determination of sink strength by regulation of assimilated partitioning, and affects grain size and yield by altering sugar metabolism in rice, including sugar composition, transport and starch accumulation $[40,41]$. Recently, OsINV2 was identified as a functionally redundant vacuolar invertase isoform as mutating it did not show any significant changes in key agronomic and physiological traits [42]. Despite the wealth of documented knowledge about vacuolar invertases in rice, the genetic relationships of the two VIN genes and the molecular interactions between VINs and grain size are largely unknown.

To further understand the molecular mechanisms that determine grain size, we identified a few genes that affect grain size in rice. Here we report a new mutant allele of OsINV3 in the indica background, named SG2, which encodes a vacuolar invertase involved in molecular sink strength determination in rice. Our work focused on the physiological role and function of VIN isogenes, OsINV2 and OsINV3. Our results suggest that both OsINV3 and OsINV2 influence grain size by regulating sucrose metabolism and that both genes are important regulatory factors required for grain size development in rice. 


\section{Results}

\subsection{Characterization of the sg2-1 and sg2-2 Mutants}

To understand how grain size is determined in rice, we selected two small seed mutants (sg2-1 and sg2-2) from EMS-mutagenized M2 populations of Yixiang 1B (WT). When compared with WT, the $s g 2-1$ and sg2-2 mutants exhibited a smaller grain phenotype (Figure 1A,B). Grain length of WT, sg2-1 and sg2-2 was $10.04 \mathrm{~mm}, 9.05 \mathrm{~mm}$, and $9.08 \mathrm{~mm}$, respectively (Figure 1C and Table 1). The $s g 2-1$ and $s g 2-2$ mutants showed reduced grain width and grain thickness (14.65\% and $19.05 \%$ for grain width, $8.78 \%$ and $13.17 \%$ for grain thickness, respectively) compared to WT (Figure 1D,E and Table 1). Moreover, the 1000-grain weight of $s g 2-1$ and $s g 2-2$ was markedly reduced by $38.75 \%, 40.67 \%$ as compared to the WT (Figure 1F and Table 1). No obvious difference was observed in any other agronomic traits (Figure 1A,G-J and Table 1). These results indicate that SG2 influences grain size and weight in rice.
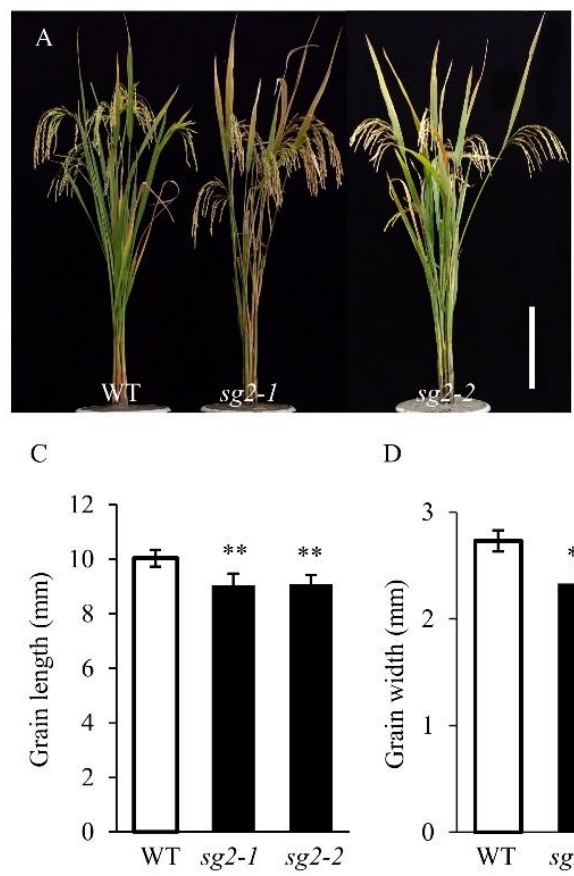

G

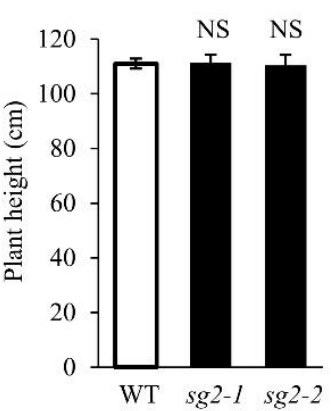

$\mathrm{D}$

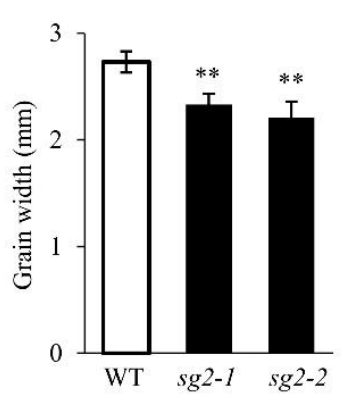

$\mathrm{H}$

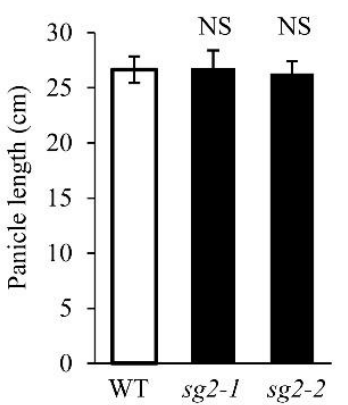

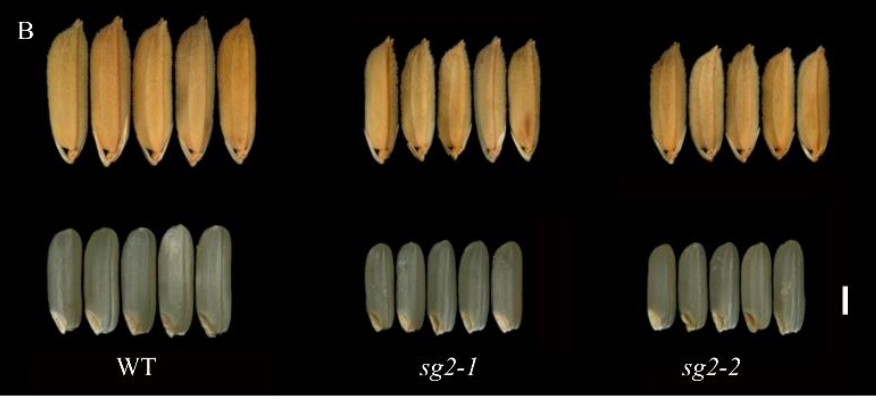

$\mathrm{E}$
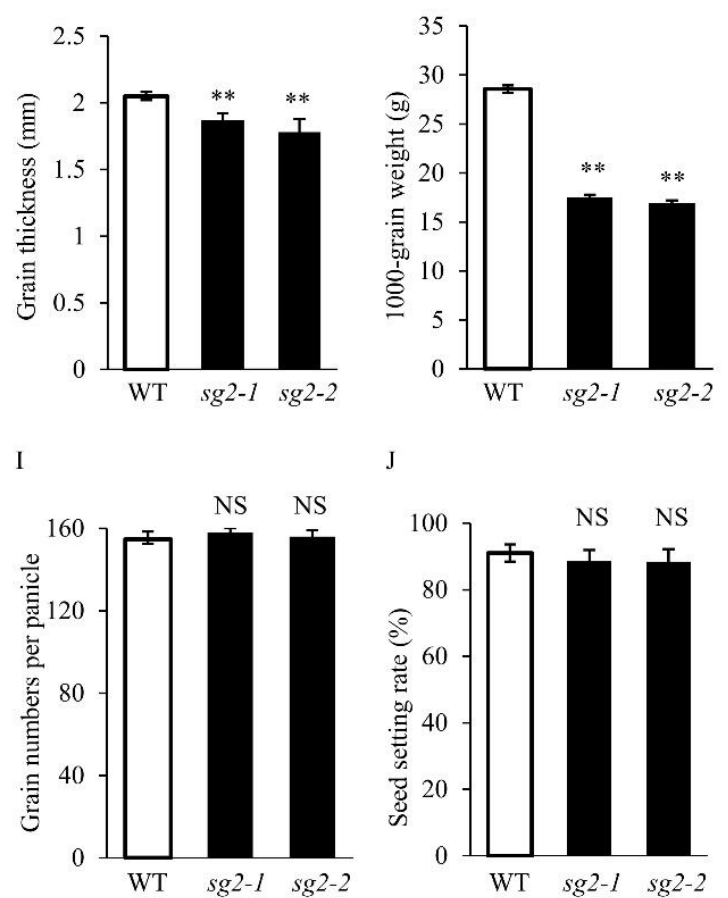

$\mathrm{J}$

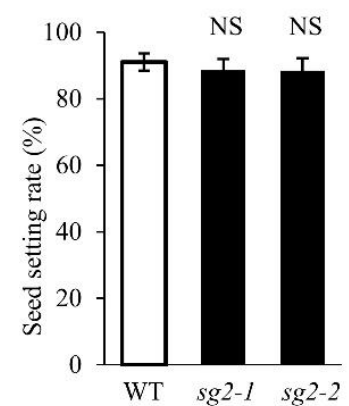

Figure 1. Phenotypic analysis of $s g 2$ mutants. (A) Plant comparison of wild-type (WT), sg2-1, sg2-2 at the maturity stage. Bar $=20 \mathrm{~cm}$. (B) Morphology of grain shape in WT, sg2-1, sg2-2. Bar $=2 \mathrm{~mm}$. Statistical data of the grain length $(\mathbf{C})$, grain width $(\mathbf{D})$, grain thickness (E), 1000-grain weight (F), plant height $(\mathbf{G})$, panicle length $(\mathbf{H})$, grain numbers per panicle (I), and seed setting rate (J) in WT and $s g 2$ mutants. Data are given as means \pm SD. Student's t-test was used to generate the $p$ values; ${ }^{* *}$ and NS indicate $p<0.01$ and no significant differences, respectively. 
Table 1. Agronomic traits of WT and sg2 mutants.

\begin{tabular}{|c|c|c|c|c|c|c|c|c|}
\hline Materials & $\begin{array}{c}\text { Grain Length } \\
(\mathrm{mm})\end{array}$ & $\begin{array}{l}\text { Grain Width } \\
(\mathrm{mm})\end{array}$ & $\begin{array}{c}\text { Grain Thickness } \\
(\mathrm{mm})\end{array}$ & $\begin{array}{l}\text { 1000-Grain } \\
\text { Weight (g) }\end{array}$ & $\begin{array}{l}\text { Plant Height } \\
\text { (cm) }\end{array}$ & $\begin{array}{c}\text { Panicle Length } \\
(\mathrm{cm})\end{array}$ & $\begin{array}{l}\text { Grain Numbers } \\
\text { per Panicle }\end{array}$ & $\begin{array}{c}\text { Seed Setting } \\
\text { Rate }(\%)\end{array}$ \\
\hline WT & $10.04 \pm 0.31$ & $2.73 \pm 0.10$ & $2.05 \pm 0.03$ & $28.57 \pm 0.36$ & $111.00 \pm 1.82$ & $26.64 \pm 1.21$ & $154.70 \pm 3.66$ & $91.01 \pm 2.61$ \\
\hline$s g 2-1$ & $9.05 \pm 0.43^{* *}$ & $2.33 \pm 0.10^{* *}$ & $1.87 \pm 0.05^{* *}$ & $17.5 \pm 0.29$ ** & $111.40 \pm 2.97$ & $26.79 \pm 1.59$ & $158.00 \pm 2.18$ & $88.61 \pm 3.29$ \\
\hline sg2-2 & $9.08 \pm 0.35^{* *}$ & $2.21 \pm 0.15^{* *}$ & $1.78 \pm 0.10^{* *}$ & $16.95 \pm 0.25^{* *}$ & $110.50 \pm 3.69$ & $26.32 \pm 1.10$ & $156.00 \pm 3.04$ & $88.46 \pm 3.77$ \\
\hline
\end{tabular}

Data are given as means \pm SD. Student's t-test was used to generate the $p$ values; ${ }^{* *}$ indicate $p<0.01$. 


\section{2. sg2 Regulates Spikelet Hull Development by Modulating Cell Expansion}

The size of a grain has been known to be restricted by its spikelet hull, which may set an upper limit for final grain size [4]. The growth of spikelet hulls is coordinately determined by cell proliferation and expansion. We therefore examined outer epidermal cells in spikelet hulls in WT, sg2-1 and sg2-2 by scanning electron microscopy (SEM). As shown in Figure 2A-C, the cell densities in sg2-1 and sg2-2 were significantly higher than that of WT, the cells were closely stacked, and the cell size was smaller. The cell length, cell width and cell area in sg2-1 and sg2-2 were significantly decreased (Figure 2D-F and Table S1) in agreement with the observations by SEM. Cell proliferation and cell expansion processes have been known to coordinately regulate spikelet hull growth [5]. We investigated expression of several known genes that determine grain size genes and are involved in the regulation of cell expansion, such as GS2 [43], GL7 [44], SRS5 [45], SRS3 [21], and SMG11 [46]. We further investigated the expression levels of some known genes responsible for grain size involved in the regulation of cell proliferation, including GS5 [47], GS3 [48], GW2 [7], and GL3 [49]. The cell expansion genes were up-regulated in young panicles of $s g 2-1$ and $s g 2-2$ mutants, while the cell proliferation genes showed no difference in expression when compared to WT (Figure S1). Taken together, these results suggest that the small grain phenotypes of the $s g 2-1$ and $s g 2-2$ mutants are mainly a result of reduced cell expansion in spikelet hulls.

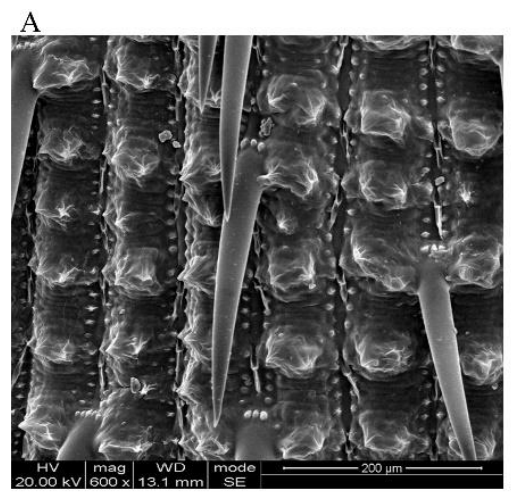

WT

$\mathrm{D}$

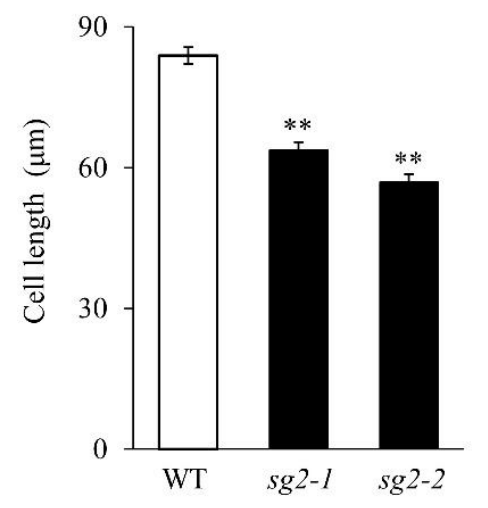

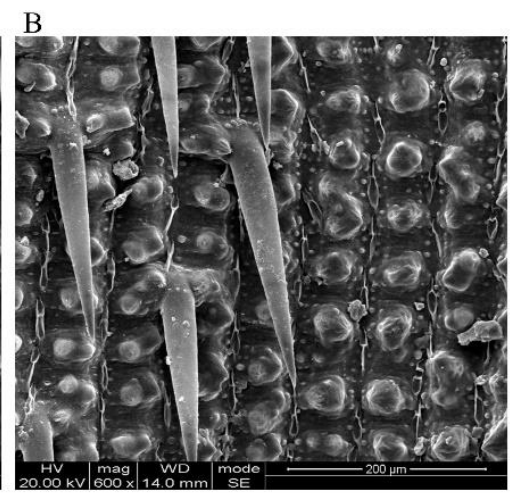

$\operatorname{sg} 2-1$

E

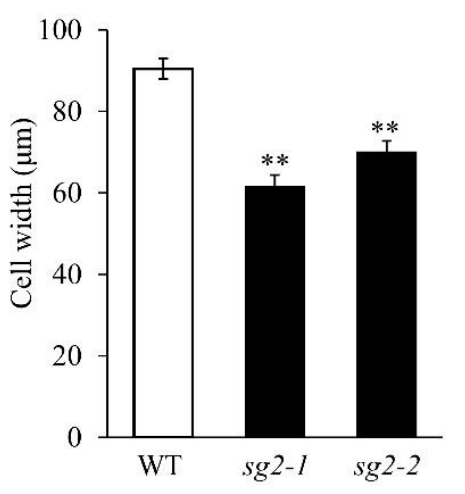

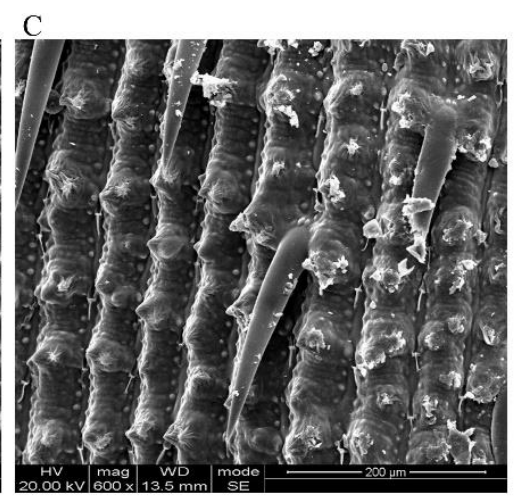

$s g 2-2$

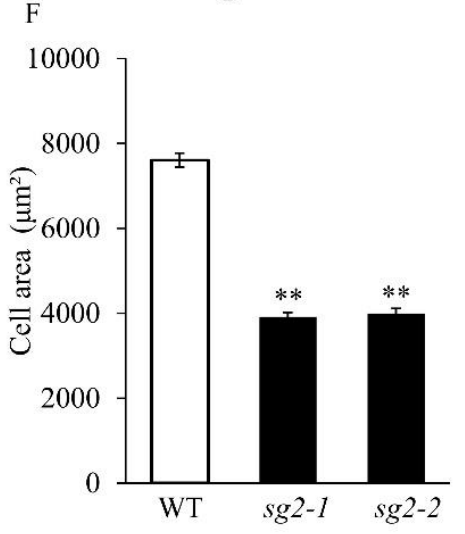

Figure 2. Histological comparison of the spikelet hulls between WT and $s g 2$ mutants. (A-C) Outer epidermal cells of the lemma observed by SEM. Scale bar, $200 \mu \mathrm{m}$. (D-F) Comparison analysis of the cell length, cell width and cell area in the outer epidermal cells. Data are given as means \pm SD. Student's t-test was used to generate the $p$ values; ${ }^{* *}$ indicate $p<0.01$.

\subsection{Genetic Analysis and Map-Based Cloning of the sg2-1 and sg2-2 Mutants}

To identify the gene responsible for the $s g 2$ phenotype, we obtained $F_{1}$ and $F_{2}$ progenies from the crosses between mutants and WT. We found that the morphology of all $\mathrm{F}_{1}$ plants was similar to WT. In each of the $F_{2}$ populations, the ratio of normal (WT) to small grains (sg2 mutants) was 
around 3:1 (Table S2). Since sg2-1 mutant had phenotypes very similar to $s g 2-2$, we suspected that $s g 2-1$ and $s g 2-2$ are allelic mutants. The reciprocal crosses of $s g 2-1$ and $s g 2-2$ showed progeny with mutant phenotypes (Figure S2A). The grain size of $s g 2-1 / s g 2-2$ and $s g 2-2 / s g 2-1 \mathrm{~F}_{1}$ progeny did not differ significantly from the $s g 2$ mutants (Figure S2B). Additionally, the grain length, grain width, grain thickness and 1000-grain weight of $s g 2-1 / s g 2-2$ and sg2-2/sg2-1 of $\mathrm{F}_{1}$ progeny were not significantly different when compared to the sg2 mutants (Figure S2C-F). Overall, genetic analyses showed that $s g 2-1$ and $s g 2-2$ are controlled by a single recessive nuclear gene and are alleles.

The sg2 mutations were initially mapped to a region between markers Os2 and RM12338 on chromosome 2 using the above-described $\mathrm{F}_{2}$ populations (Figure $3 \mathrm{~A}$ ) and were further narrowed down to a 130-kb genomic DNA region between Os2 and RM7252 (Figure 3B). Sequence comparison showed several SNPs between WT plants and the mutant pool. A single linked SNP (SNP-index $=1$ ) was found by comparing sequences between the pooled mutants and WT in the candidate region (Figure 3C). The SNP was localized to the second exon of LOC_Os02g01590 (Figure 3D). A G-to-A single base substitution was detected at the 878 th base in $s g 2-1$, that resulted in a premature stop codon. To define the molecular characteristics of the $s g 2-2$ allele, the $s g 2-2$ allele was amplified from genomic DNA by PCR and sequenced. Comparison of the sequences of WT and sg2-2 revealed that $s g 2-2$ has a $C$ to $T$ substitution at base 421, resulting in a Proline (P) to Serine (S) change at amino acid 141. These results suggested that LOC_Os02g01590 represents the SG2 gene. This gene encodes a vacuolar invertase, OsINV3, which is involved in sink strength determination, mainly by regulation of grain size, assimilates partitioning to grain and affects grain size by altering sugar metabolism [40,41].

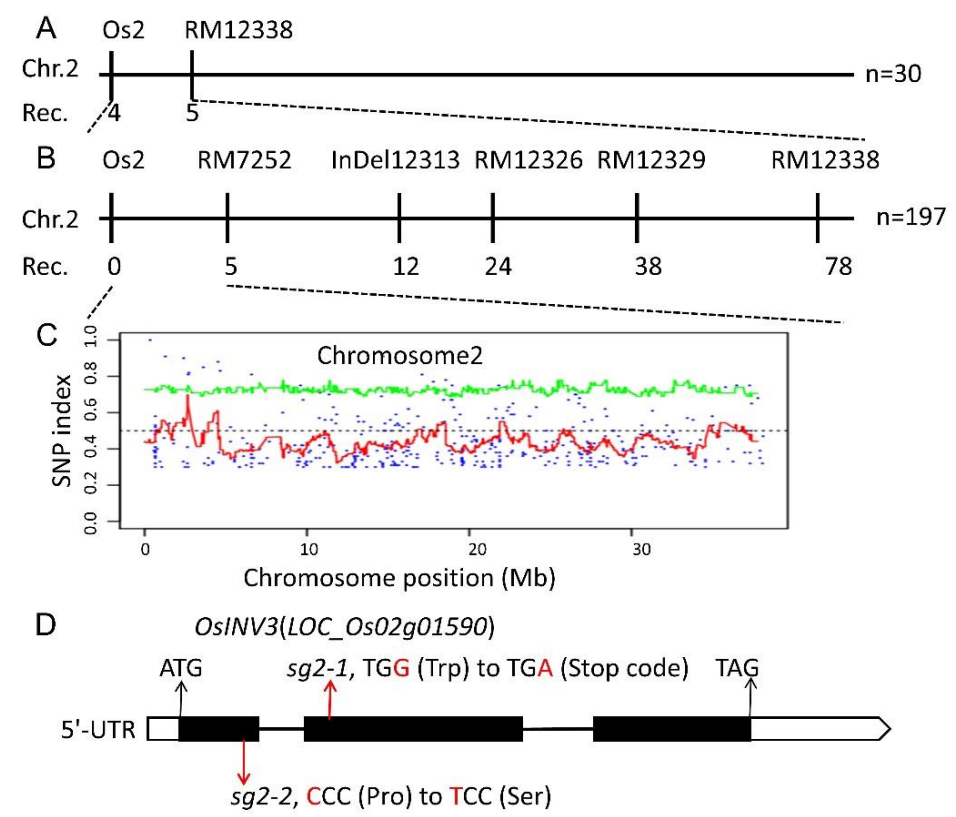

Figure 3. Positional cloning of SG2. (A) The SG2 gene is located on chromosome 2 between InDel marker Os2 and SSR marker RM12338. (B) Then SG2 gene is delimited to the region between Os2 and RM7252 using $197 \mathrm{~F}_{2}$ mutant individuals. (C) Manhattan plot of chromosome 2. (D) The gene structure of SG2. Black boxes, lines and white boxes represent exons, introns and the untranslated regions, respectively. The start codon (ATG) and the stop codon (TAG) are indicated. The sg2 mutations in the SG2 gene is shown.

\subsection{Confirmation of the sg2/OsINV3 Gene}

To confirm that $s g 2$ was a mutation in OsINV3, we performed a complementation experiment in the sg2-1 background. A plasmid carrying wild-type gene of LOC_Os02g01590 driven by its native promoter (proINV3::INV3) was introduced into the sg2-1 mutant. Five complementation transgenic lines (C1-C5) were obtained (Figure 4A). All transgenic lines complemented the sg2 phenotype (Figure 4B). 
The grain length, grain width and 1000-grain weight of $\mathrm{C} 1, \mathrm{C} 2, \mathrm{C} 3, \mathrm{C} 4$, and C5 did not differ as compared to WT (Figure 4C-E). The relative expression of OsINV3 in the sg2 mutants was significantly reduced in comparison to the $\mathrm{WT}$, and the relative expression in complementation lines (C1-C5) reverted back to WT levels (Figure S3A). In addition, a T-DNA insertion mutant, inv3, was obtained in the background of Hwayoung (HY), a japonica variety. In inv3, the T-DNA was inserted between the second and third exons (Figure 5A,B). Compared to HY, the inv3 T-DNA insertion mutant displayed reduced plant height, smaller grain size, and drastically reduced 1000-grain weight (Figure 5C-H, Table S3). We also generated knockout mutants (KOs) of OsINV3 using the CRISPR/Cas9 genome editing system in the background of Zhonghua11 (ZH11) (Figure 6A). Five independent homozygous transgenic plants (KO1-KO5) with different mutations were generated that showed smaller grain size (Figure 6B,D-F, Table S4). The relative expression of OsINV3 in the KOs was significantly decreased compared to ZH11 (Figure S3B). Three overexpression transgenic lines (OEs) were also obtained in ZH11 and their grain phenotypes were characterized (Figure 6C). Comparable to ZH11, the overexpression transgenic lines (OE1, OE2, and OE3) showed significant increases in grain length, width and weight (Figure 6G-I and Table S4). The relative expression of OsINV3 in the OEs was significantly increased compared to ZH11 (Figure S3B). These results together confirmed that LOC_Os02g01590 is indeed the SG2 gene.

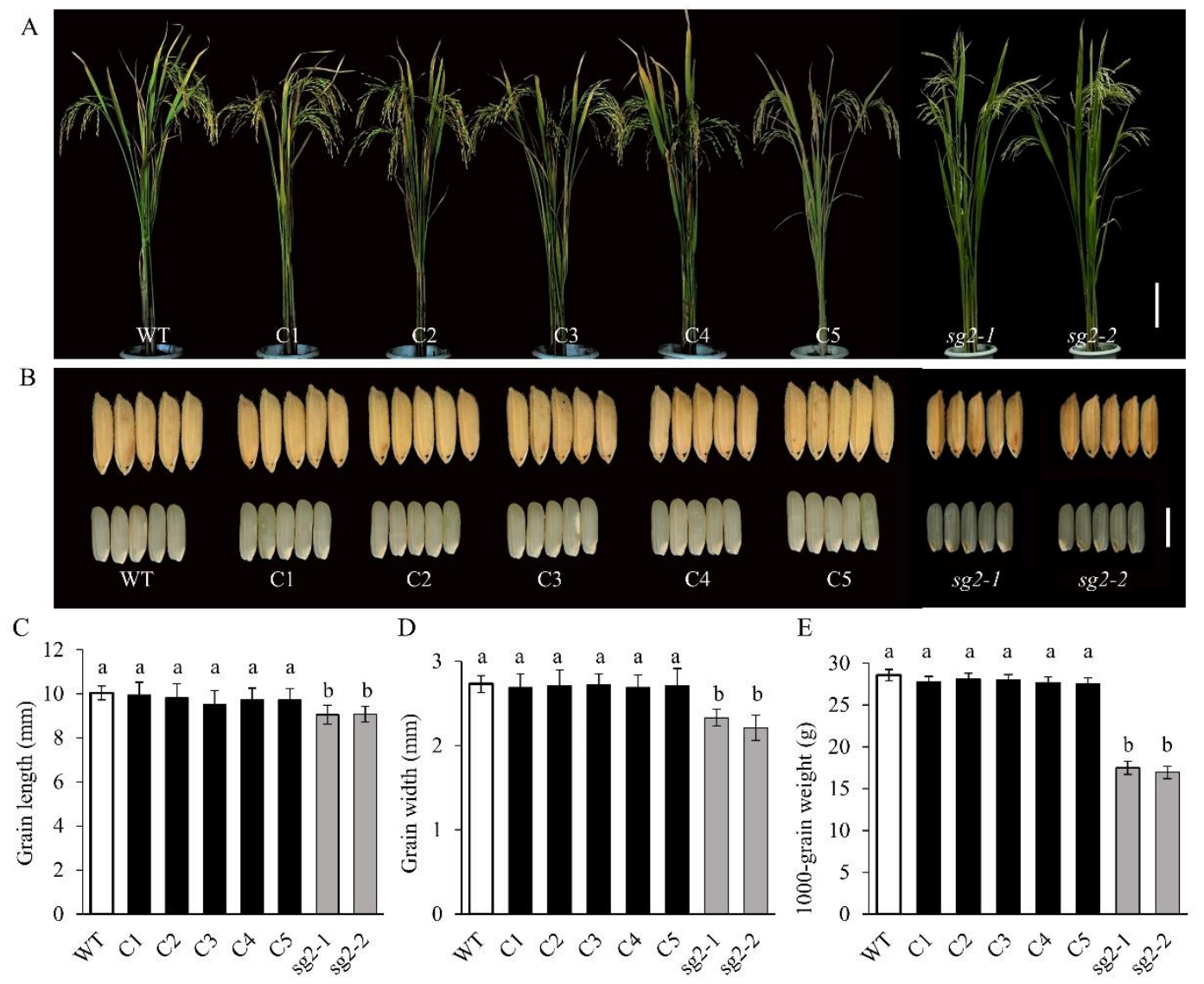

Figure 4. Phenotypic characterizations of complementation lines. (A) Plant comparison of wild-type (WT), complementation lines at the maturity stage. C1-C5 represent the five complementation transgenic lines. Bar $=20 \mathrm{~cm}$. (B) Morphology of grain shape in WT, complementation lines. Bar $=2 \mathrm{~mm}$. (C-E) Statistical data of the grain length (C), grain width (D), 1000-grain weight (E) in WT and complementation lines. Data are given as means \pm SD. Different letters indicate statistically significant differences at the $p=0.01$ level by Student's t-test. 

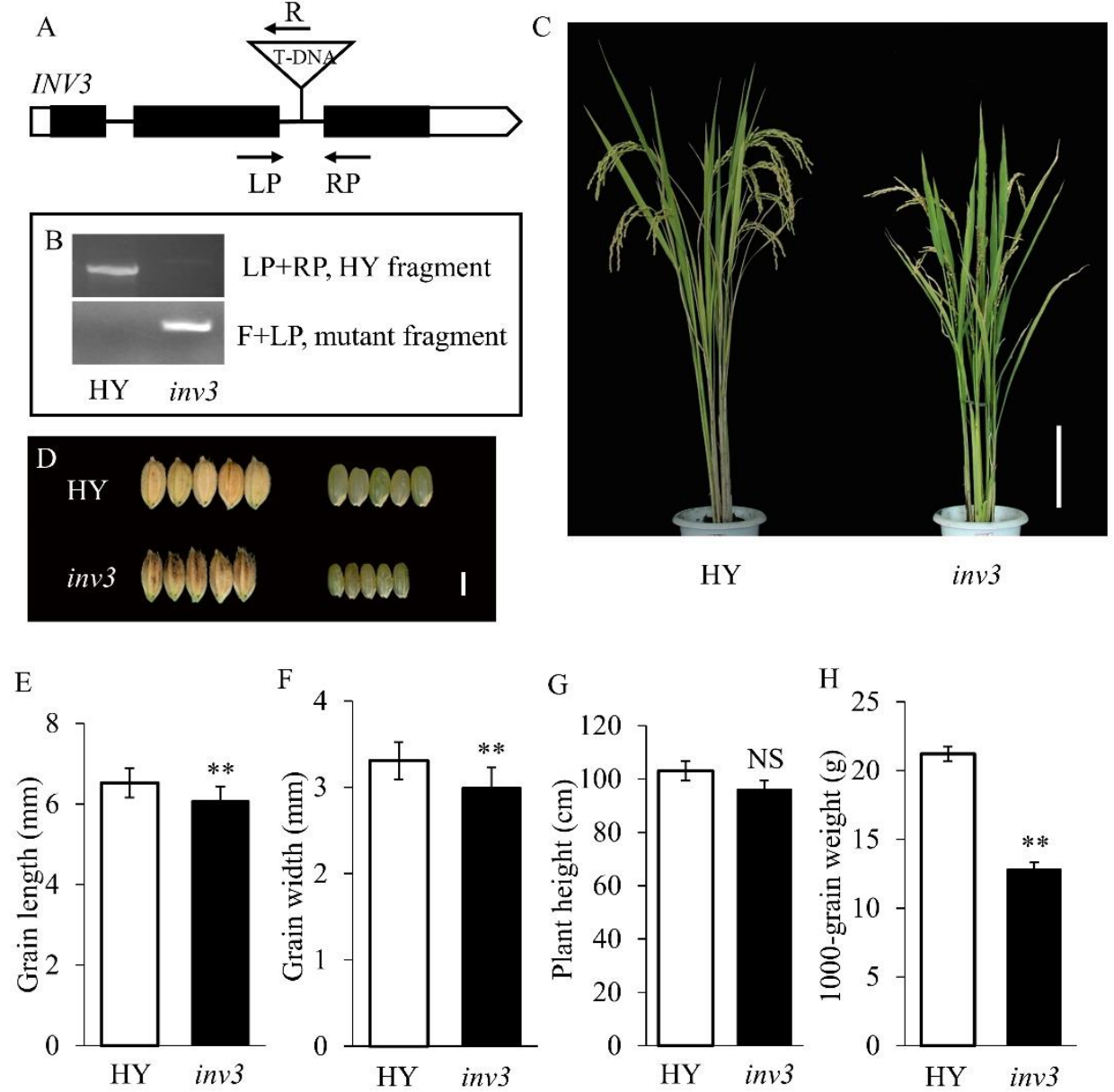

Figure 5. Phenotypic characterizations of INV3 T-DNA insertion mutant. (A) T-DNA insertion site of the inv3 mutant. The triangle indicates the T-DNA insertion site in the inv3 mutant. Black boxes, lines and white boxes represent exons, introns and the untranslated regions, respectively. (B) Gel data showing the presence of HY and inv3 alleles. (C) Plant comparison of HY, inv3 mutant at the maturity stage. Bar $=10 \mathrm{~cm}$. (D) Morphology of grain shape in HY, inv3 mutant. Bar $=2 \mathrm{~mm}$. (E-H) Statistical data of the grain length (E), grain width (F), plant height (G) 1000-grain weight (H) in WT and inv3 mutant. Data are given as means \pm SD. Student's t-test was used to generate the $p$ values; ${ }^{* *}$ and NS indicate $p<0.01$ and no significant differences, respectively.

\subsection{OsINV3 Expression Pattern and Protein Subcellular Localization}

The expression pattern of OsINV3 in various organs was investigated by quantitative real-time PCR. OsINV3 transcripts were detected in all tissues tested, with significantly higher levels in the developing young panicles and leaf blade at booting stage, but at extremely lower levels in the developing endosperm (Figure 7A). We further investigated the subcellular localization of the OsINV3 protein. A plasmid containing the yellow fluorescent protein (YFP) gene tagged to OsINV3 wild-type cDNA driven by a native promoter (INV3-YFP) was transiently expressed in rice protoplast. The INV3-YFP fusion protein localized to the nucleus (Figure 7B), an observation consistent with a previous report [41]. OsVIN2 has been reported to be a dual localization protein, and it is not detectable in the vacuole because the fluorescence signal is easily degraded in the acidic vacuolar lumen in the light and may be transported to the vacuole through PVCs [41,50,51]. Thus, the expression pattern of OsINV3 is consistent with the role of OsINV3 in influencing grain and panicle size. 

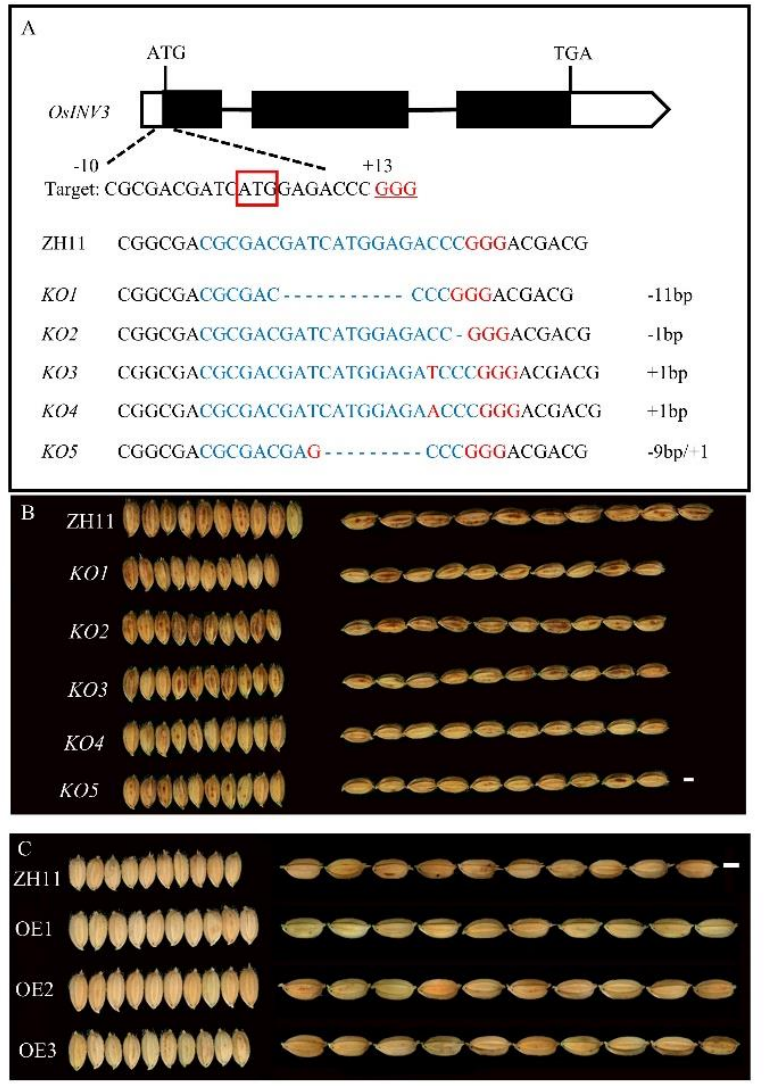

D
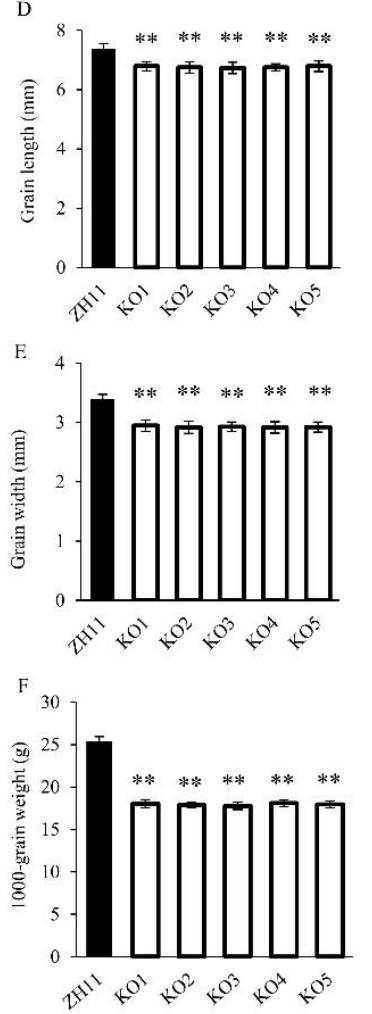
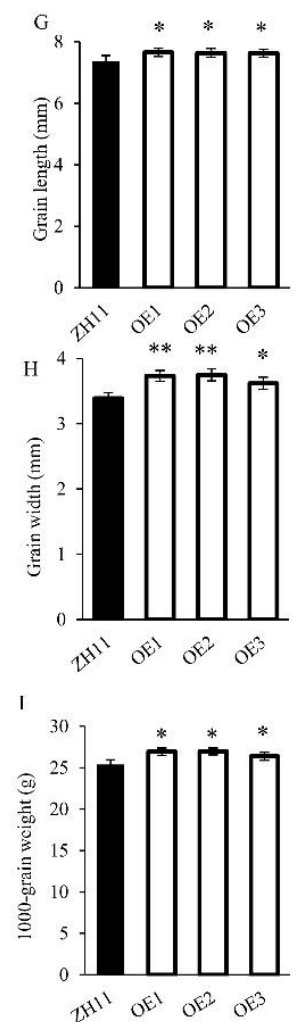

Figure 6. Genetic effects of OsINV3 KOs and OEs on grain size. (A) Schematic map of the sgRNA target site in OsINV3 and sequence alignment for KOs (KO1-KO5). Black boxes, lines and white boxes represent exons, introns and the untranslated regions, respectively. The start codon (ATG) and the stop codon (TAG) are indicated. (B) Morphology of grain shape in ZH11 and KOs. Bar = $2 \mathrm{~mm}$. (C) Morphology of grain shape in ZH11 and OEs (OE1-OE3). Bar = $2 \mathrm{~mm}$. (D-F) Statistical data of the grain length (D), grain width (E), 1000-grain weight (F) in ZH11, KOs. (G-I) Statistical data of the grain length (G), grain width (H), 1000-grain weight (I) in ZH11, OEs. Data are given as means \pm SD. Student's t-test was used to generate the $p$ values; ${ }^{* *},{ }^{*}$ indicate $p<0.01, p<0.05$, respectively.

\subsection{Interaction between OsINV3 and OsINV2 in Grain Size Regulation}

To further evaluate the underlying mechanisms of OsINV3 and OsINV2 in regulating grain size, we constructed a phylogenetic tree of all invertase proteins in rice. The analyses revealed a close phylogenetic relationship between OsINV2 and OsINV3 (Figure S4). We also obtained a T-DNA insertion mutant of OsINV2 and generated double knockout (KO) mutants of INVs (OsINV2 and OsINV3) using CRISPR/Cas9. The T-DNA insertion mutant inv2 was obtained in the Dongjing (DJ) background, a japonica variety. In inv2, the T-DNA was inserted between the first and second exons (Figure 8A,B). When compared with DJ, inv2 showed no visible differences in grain length, grain width or 1000-grain weight (Figure $8 \mathrm{C}-\mathrm{H}$ and Table 2). For subcellular localization analysis of OsINV2, we generated an INV2-GFP fusion construct driven by the CaMV 35S promoter and performed a transient transfection assay in rice protoplasts. Fluorescent signals of INV2-GFP were detected in the nucleus, consistent with known OsINV3 localization (Figure S5). 
A

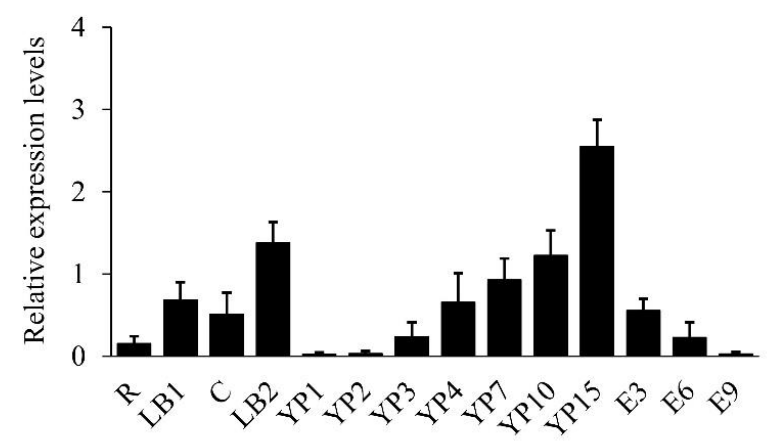

B

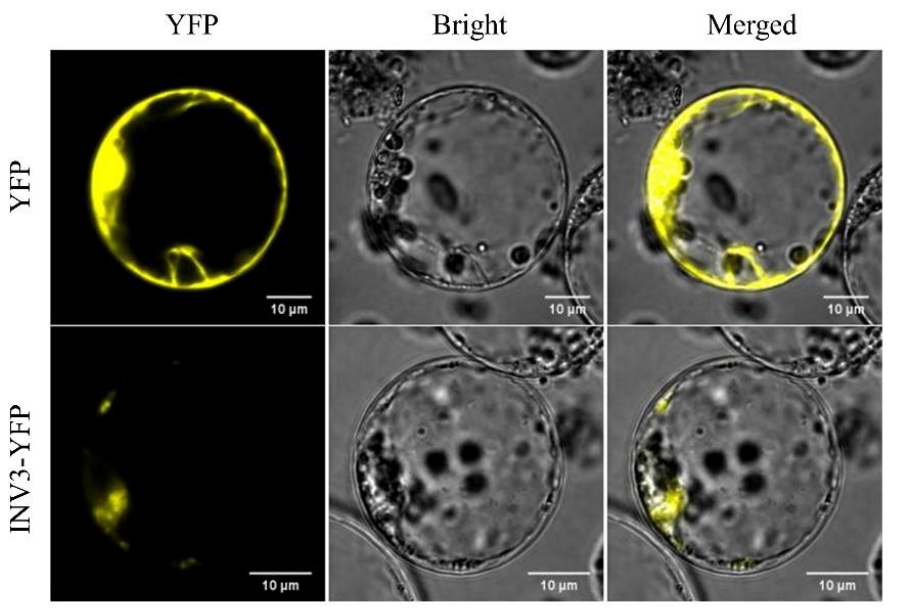

Figure 7. OsINV3/SG2 expression pattern and protein subcellular localization. (A) Quantitative real-time PCR analysis of OsINV3 expression in various tissues of wild-type plants. R, LB1, root and leaf blade at seedling stage; C, LB2, LS, culm, leaf blade, leaf sheath at booting stage, respectively; YP1-YP15, young panicles with different length $(\mathrm{cm})$. E3-E9, endosperm, the number indicates the days after fertilization. Data are given as mean \pm SD. $(n=3)$. OsActin was used as the control. (B) Subcellular localization of OsINV3 observed in rice protoplasts. Scale bar, $10 \mu \mathrm{m}$.

Table 2. Agronomic traits of Dongjing (DJ) and inv2.

\begin{tabular}{ccccc}
\hline Materials & Grain Length $(\mathbf{m m})$ & Grain Width $(\mathbf{m m})$ & 1000-Grain Weight $(\mathrm{g})$ & Plant Height $(\mathbf{c m})$ \\
\hline DJ & $6.53 \pm 0.43$ & $3.19 \pm 0.24$ & $22.04 \pm 1.03$ & $108.02 \pm 1.62$ \\
inv2 & $6.63 \pm 0.33$ & $3.12 \pm 0.30$ & $21.32 \pm 1.10$ & $105.11 \pm 1.52$ \\
\hline
\end{tabular}

Data are given as means $\pm \mathrm{SD}$. Student's t-test was used to generate the $p$ values.

Additionally, we designed two sgRNA target sites (target 1 and target 2) in the first exon of OsINV3 and third exon of OsINV2 (Figure S6A). Interestingly, we obtained OsINV2 KOs (INV2 ${ }^{K O}-1$, $\left.I N V 2^{K O}-2\right)$, OsINV3 KO (INV3 $\left.{ }^{K O}\right)$ and double knockout mutants $\left(I N V 3^{K O} I N V 2^{K O}-1, I N V 3^{K O} I N V 2^{K O}-2\right)$ in the ZH11 background (Figure S6B). When compared with ZH11, the OsINV2 KOs showed the same grain size traits, but $I N V 3^{K O}$ and $I N V 3^{K O} I N V 2^{K O}$ displayed obviously reduced grain size (Figure $9 \mathrm{~A}, \mathrm{~B}$ ). Compared to $\mathrm{ZH} 11, I N V 3^{K O}$, INV $3^{K O} I N V 2^{K O}-1$, and $I N V 3^{K O} I N V 2^{K O}-2$ showed dramatically reduced grain length and grain width, while $I N V 2^{K O}-1$ and $I N V 2^{K O}-2$ showed no difference (Figure 9C,D and Table 3). Moreover, the 1000-grain weight of $I N V 3^{K O}, I N V 3^{K O} I N V 2^{K O}-1$, and $I N V 3^{K O} I N V 2^{K O}-2$ was markedly reduced by $27.11 \%, 33.43 \%$, and $33.56 \%$, respectively as compared to ZH11, while the 1000-grain weight of $I N V 2^{K O}-1$ and $I N V 2^{K O}-2$ showed no difference (Figure $9 \mathrm{E}$ and Table 3). Compared with $I N V 3^{K O}$, the two double mutants (INV3 $\left.{ }^{K O} I N V 2^{K O}-1, I N V 3^{K O} I N V 2^{K O}-2\right)$ showed markedly reduced grain width, grain length and 1000-grain weight, with grain length decreased by about $6.16 \%$ and $6.51 \%$, and grain width decreased by about $5.00 \%$ and $5.31 \%$, and 1000 -grain weight 
decreased by about $8.68 \%$ and $8.86 \%$ respectively (Figure $9 \mathrm{C}-\mathrm{E}$ and Table 3 ), suggesting that in the absence of OsINV3, it is possible to detect a role of OsINV2 in the regulation of grain size. Furthermore, the relative expression of OsINV3 and OsINV2 in the double $K O$ mutant was significantly reduced when compared to ZH11(Figure S7).

Table 3. Agronomic traits of ZH11 and KOs.

\begin{tabular}{cccc}
\hline Materials & Grain Length $(\mathbf{m m})$ & Grain Width $(\mathbf{m m})$ & 1000-Grain Weight $(\mathbf{g})$ \\
\hline $\mathrm{ZH} 11$ & $7.36 \pm 0.19$ & $3.39 \pm 0.09$ & $25.41 \pm 0.55$ \\
$I N V 2^{K O}-1$ & $7.45 \pm 0.10$ & $3.35 \pm 0.13$ & $25.00 \pm 0.48$ \\
$I N V 2^{K O_{-}}$ & $7.38 \pm 0.16$ & $3.40 \pm 0.10$ & $24.76 \pm 0.43$ \\
$I N V 3^{K O}$ & $6.75 \pm 0.18^{* *}$ & $2.92 \pm 0.09^{* *}$ & $18.52 \pm 0.31^{* *}$ \\
$I N V 3^{K O} I N V 2^{K O}-1$ & $6.34 \pm 0.15^{* *}$ & $2.78 \pm 0.07^{* *}$ & $16.91 \pm 0.29^{* *}$ \\
$I N V 3^{K O} I N V 2^{K O}-2$ & $6.31 \pm 0.11^{* *}$ & $2.77 \pm 0.06^{* *}$ & $16.88 \pm 0.30^{* *}$ \\
\hline
\end{tabular}

Data are given as means \pm SD. Student's t-test was used to generate the $p$ values; ${ }^{* *}$ indicate $p<0.01$.
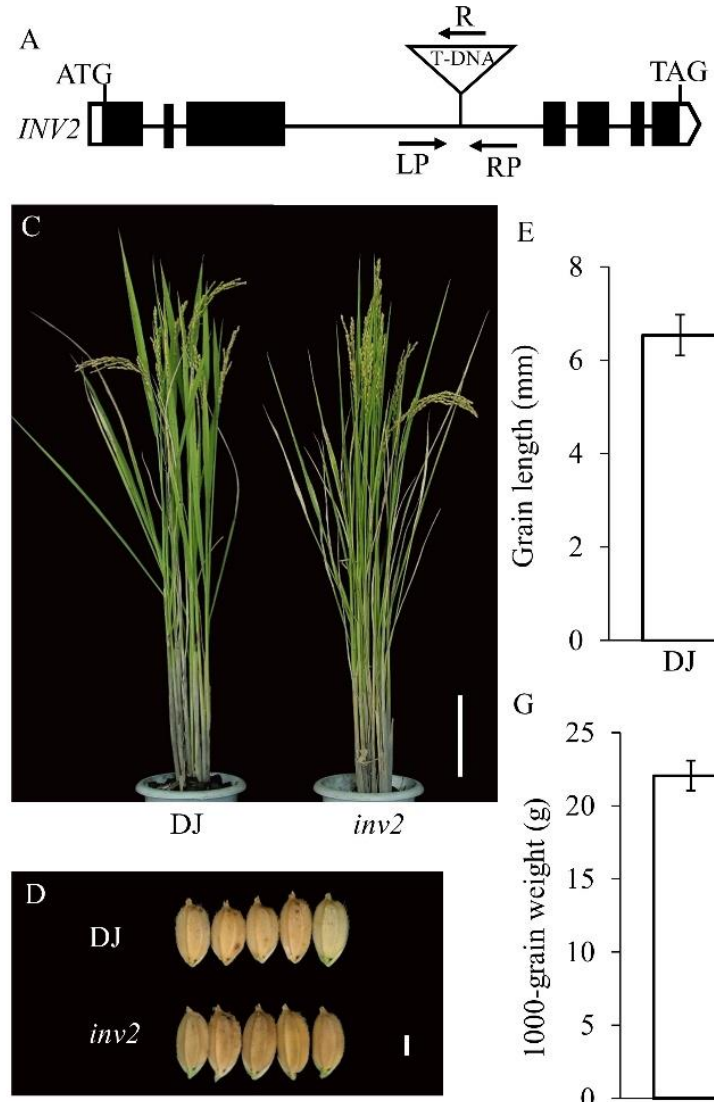

E
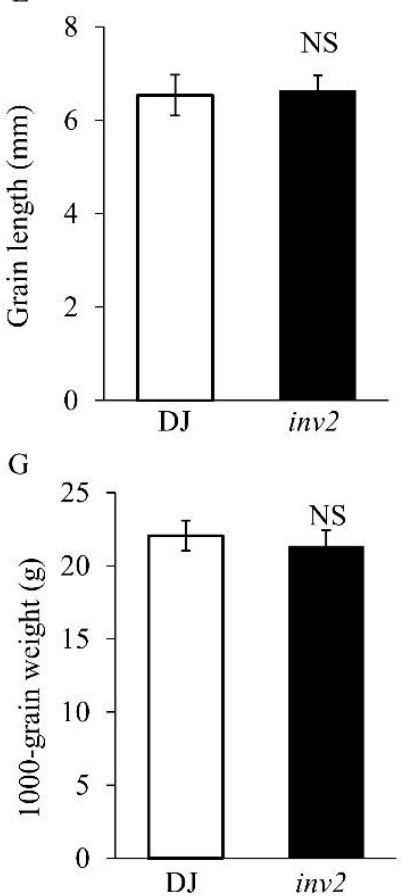

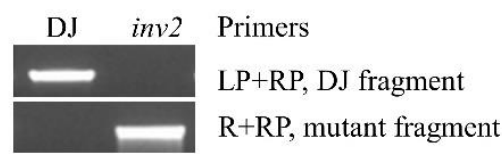

$\mathrm{F}$

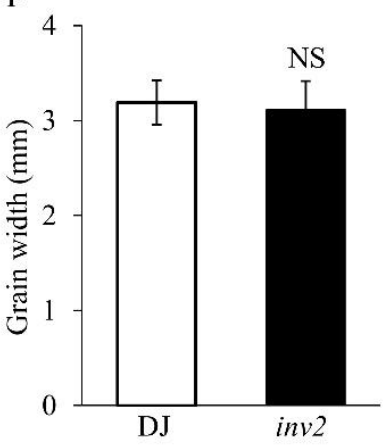

$\mathrm{H}$

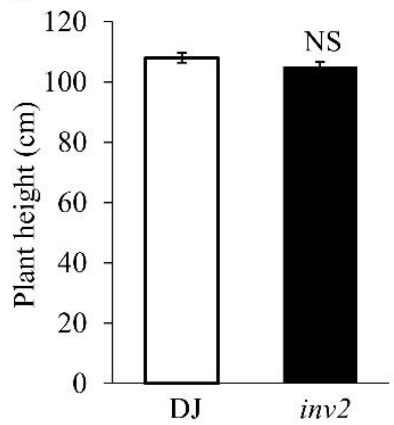

Figure 8. Phenotypic characterizations of INV2 T-DNA insertion mutant. (A) T-DNA insertion site of the inv 2 mutant. The triangle indicates the T-DNA insertion site in the inv2 mutant. Black boxes, lines and white boxes represent exons, introns and the untranslated regions, respectively. The start codon (ATG) and the stop codon (TAG) are indicated. (B) Gel data showing the presence of DJ and inv2 alleles. (C) Plant comparison of DJ, inv2 mutant at the maturity stage. Bar $=10 \mathrm{~cm}$. (D) Morphology of grain shape in DJ, inv2 mutant. Bar $=2 \mathrm{~mm}$. (E-H) Statistical data of the grain length (E), grain width (F), plant height (G), and 1000-grain weight (H) in DJ and inv2 mutant. Data are given as means \pm SD. Student's t-test was used to generate the $p$ values; NS indicate no significant differences. 

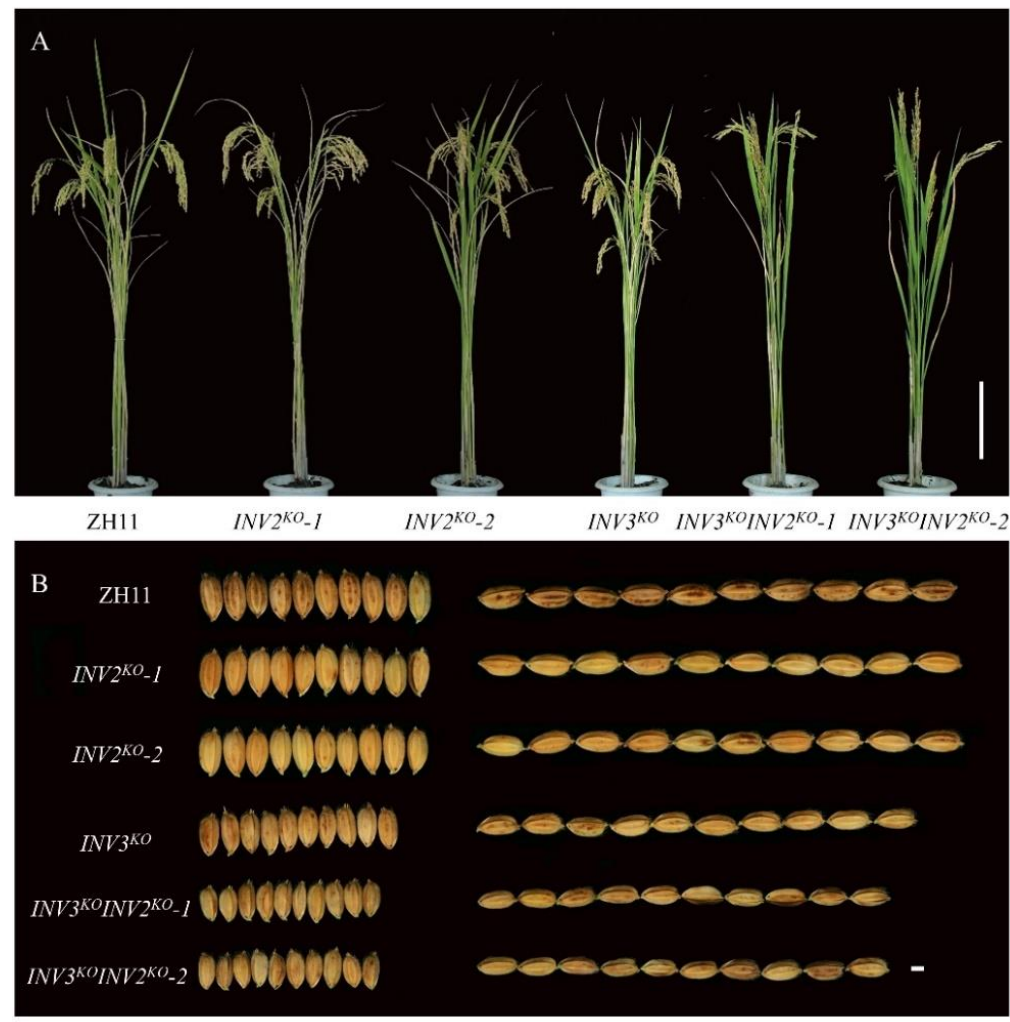

$2^{\mathrm{KO}}-2$

INV $3^{\mathrm{KO}}$ INV ${ }^{\mathrm{KO}}$ INV $2^{\mathrm{KO}}-1$ INV $3^{\mathrm{KO}} I N V 2^{\mathrm{KO}}-2$

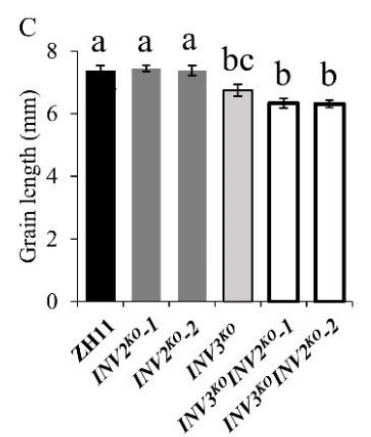

D

$\mathrm{E}$
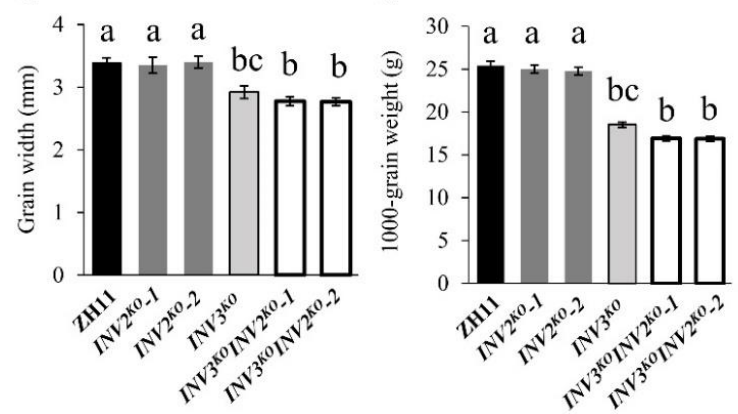

Figure 9. Genetic interactions of INV2 and INV3. (A) Plant comparison of ZH11, INV2 ${ }^{K O}-1, I N V 2^{K O}-2$, $I N V 3^{K O}, I N V 3^{K O} I N V 2^{K O_{-}}-1$, and $I N V 3^{K O} I N V 2^{K O_{-2}}$ at maturity stage. Bar $=25 \mathrm{~cm}$. (B) Morphology of grain shape in ZH11, INV2 $2_{-1}$, INV2 $2_{-2}$, INV3 ${ }^{K O}, I N V 3^{K O} I N V 2^{K O_{-}}-1$, and $I N V 3^{K O_{I N V}} 2^{K O_{-}}$. Bar $=2 \mathrm{~mm}$. (C-E) Statistical data of the grain length (C), grain width (D), 1000-grain weight (E) in $\mathrm{ZH} 11, I N V 2^{K O_{-}}-1, I N V 2^{K O_{-}}, I N V 3^{K O}, I N V 3^{K O_{I N V}} 2^{K O_{-}}$, and $I N V 3^{K O} I N V 2^{K O_{-}}$. Data are given as means \pm SD. Different letters indicate statistically significant differences at the $p=0.01$ level by Student's t-test.

To further explore the mechanisms controlling grain size, we examined outer epidermal cells in spikelet hulls in ZH11, INV2 $2^{K O}, I N V 3^{K O}$, and $I N V 3^{K O} I N V 2^{K O}$ by SEM. In contrast to ZH11, the cell length, cell width and cell area of the $I N V 3^{K O}$ and $I N V 3^{K O} I N V 2^{K O}$ were significantly reduced, while $I N V 2^{K O}$ showed no change in cell length, cell width and cell area (Figure S8). Collectively, these results suggest that OsINV3 and OsINV2 affect grain size, resulting in reduced grain size.

\subsection{Analyses of the Physiological Role of VINs}

As a major product of photosynthesis, sucrose is a key factor in crop yield. Vacuolar invertases are responsible for degradation of sucrose. To explore the physiological roles of OsINV3 and OsINV2 in determining grain size, we evaluated the invertase activities of CIN, VIN, CWIN, and measured 
the sugar composition of $\mathrm{ZH} 11, I N V 2^{K O}, I N V 3^{K O}$, and $I N V 3^{K O} I N V 2^{K O}$ in young panicles, at heading stage and the flag leaf at heading stage. Compared to ZH11, the CWIN, VIN, and CIN activities of the $I N V 3^{K O} I N V 2^{K O}$ were markedly reduced in young panicles and at heading stage, whereas the three invertase activities showed no difference in the flag leaf at heading stage (Figure 10A). The CIN and VIN activities were lower in $I N V 2^{K O}$ and INV3 ${ }^{K O}$ mutants, whereas the CWIN activities were higher in the ZH11 and VINs $K O$ mutants $\left(I N V 2^{K O}\right.$ and $\left.I N V 3^{K O}\right)$ in young panicles and at heading stage (Figure 10A). Moreover, the invertase activities of the three isoforms in $I N V 2^{K O}$ and $I N V 3^{K O}$ mutants showed no difference in the flag leaf at heading stage (Figure 10A). The results of the analysis of sugar composition showed that glucose and fructose contents in young panicles and at heading stage (panicles and flag leaf) were lower in the $I N V 3^{K O}$ mutant and the $I N V 3^{K O} I N V 2^{K O}$ double mutant when compared to the $\mathrm{ZH} 11$, whereas the $I N V 2^{K O}$ mutant showed no difference (Figure 10B). The sucrose content was higher in all $\mathrm{KO}$ mutants (INV2 ${ }^{\mathrm{KO}}$, INV $3^{K O}$, and $\left.I N V 3^{K O} I N V 2^{K O}\right)$ when compared with ZH11 (Figure 10B). As reported previously, starch, which accounting for more than $70 \%$ of the final dry weight of mature grains, is synthesized from hexose units derived from sucrose [52]. To understand the influence of OsINV2 and OsINV3 on starch metabolism, we tested the starch contents of mature grains of KOs. The total starch content was not different between $\mathrm{ZH} 11$ and $\mathrm{KOs}$ grains, while the amylose content decreased by $3 \%-6 \%$ in grains from KOs (Figure S9). These results show that sugar composition and starch constitution are affected in the $I N V 2^{K O}, I N V 3^{K O}$, and $I N V 3^{K O} I N V 2^{K O}$ mutants. This difference is owing to increased sucrose accumulation and reduced hexose production due to changes in invertase activities and starch constitution.

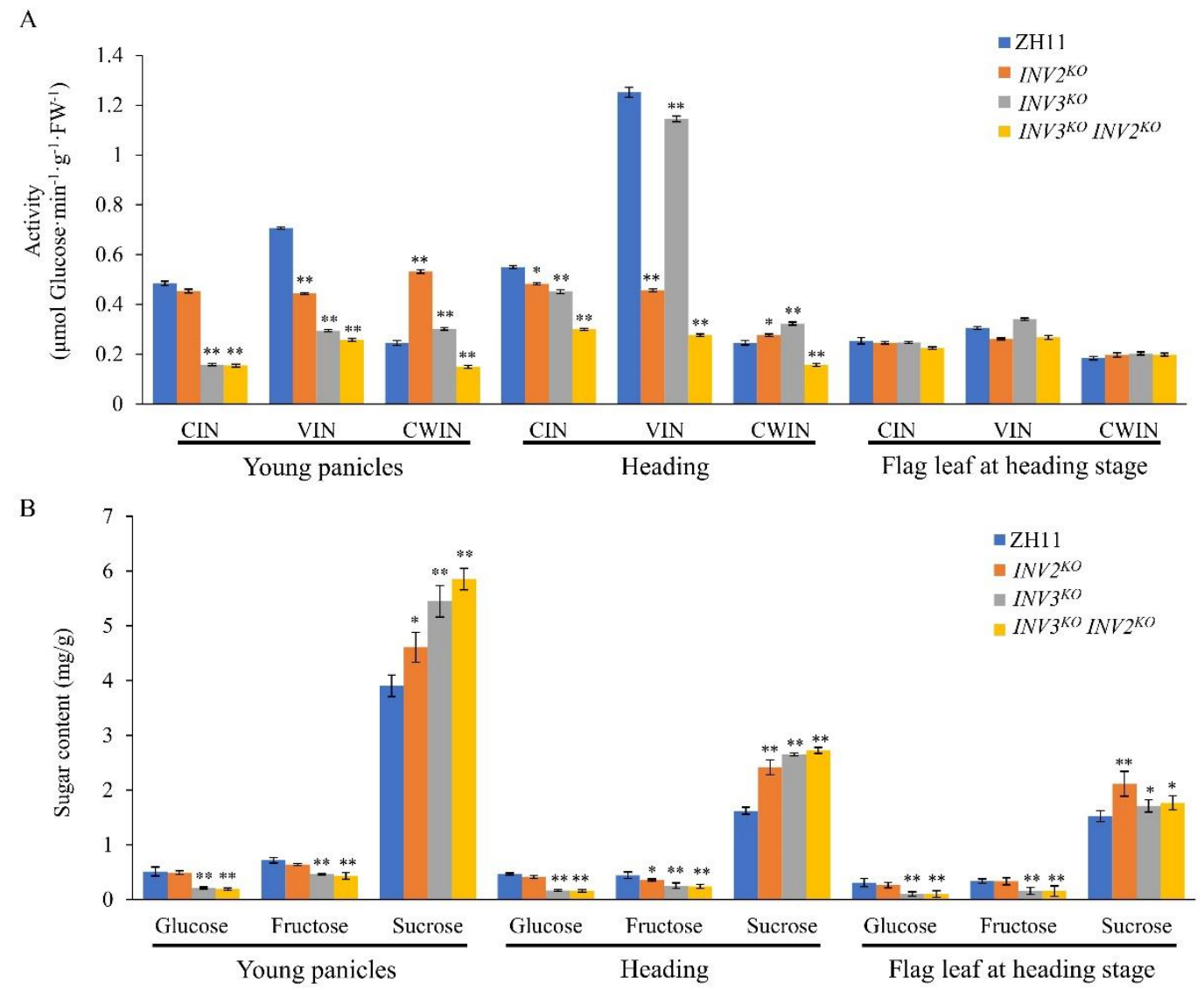

Figure 10. Comparisons of invertase activity and sugar content of $\mathrm{ZH} 11, I N V 2^{K O}, I N V 3{ }^{K O}$ and $I N V 3^{K O} I N V 2^{K O}$. Activities of three invertase isoforms (CIN, VIN, CWIN) (A) and sugar content (B) in young panicles, heading and flag leaf at heading stage of $\mathrm{ZH} 11, I N V 2^{K O}, I N V 3^{K O}$, and $I N V 3^{K O} I N V 2^{K O}$. Data are given as means \pm SD. Student's t-test was used to generate the $p$ values; ${ }^{* *},{ }^{*}$ indicate $p<0.01$, $p<0.05$, respectively. 


\section{Discussion}

\section{1. sg2 is a Novel Mutant Allele of OsINV3}

Grain size mutants are ideal to investigate the molecular functions and regulatory mechanisms that determine grain size. In rice, several factors that control grain size have been identified, but the mechanisms remain largely unknown. In this study, we identified SG2, which encodes a vacuolar invertase, and is a novel allele of OsINV3, also known as OsVIN2 [40,41]. The sg2-1 and sg2-2 mutants showed reduced grain length, grain width, and 1000-grain weight (Figure 1). Cell proliferation and cell expansion processes have been known to coordinately regulate spikelet hull growth [5]. Moreover, many studies have showed that VINs play key roles in plant growth by modulating cell expansion $[33,53,54]$. At the cellular level, the cell size of $s g 2-1$ and $s g 2-2$ mutants was affected by cell expansion in spikelet hulls (Figure 2), which is consistent with a previous report [41]. Map-based cloning and Mutmap analysis demonstrated that a SNP in the exon of OsINV3 resulted in the mutant phenotype (Figure 3). Generally, VIN contains two key functional domains, NDPN and WECVD, which are essential for its catalytic activity [28]. A SNP mutation in sg2-1 and sg2-2 caused disruptions in the key function domains WECVD and NDPN, respectively, resulting in a nonfunctional invertase that eventually led to small seeds. The sg2-1 and sg2-2 showed phenotypes similar to the inv3 alleles that have been shown to produce small grains by insertion mutations or by natural mutations $[40,41]$. Regardless of the nature of the mutation, the OsINV3 mutants display small grain size, with OsINV3 encoding a nonfunctional invertase. In agreement with previous studies, the OsINV3 expression was found to be constitutive in different tissues (Figure 7). Furthermore, our results revealed that overexpression of OsINV3 causes an increase in grain size, grain weight and grain yield (Figure 6C,G-I), indicating that this gene is a promising target for rice yield improvement. Together, these results suggest a novel and important role for SG2/INV3 in grain size regulation.

\subsection{Genetic Effect between OsINV3 and OsINV2 in the Regulation of Grain Size}

Vacuolar invertases have been proposed to regulate cell expansion, osmotic pressure, sugar signals, sucrose accumulation, and sucrose concentration, especially during the expansion phases of sink organs [32]. In rice, two VIN isogenes, OsINV2 and OsINV3, have been identified. The previously reported alleles of OsINV3 have been shown to cause small grain size [40,41]. On the other hand, OsINV2 was reported to be a functionally redundant vacuolar invertase isoform and showed no significant changes in key agronomic and physiological traits [42]. Both OsINV3 and OsINV2 play key roles in regulating traits related to grain yield in plant growth and development. Despite knowledge about these genes as outlined above, the genetic relationships of the two VIN genes and the molecular interactions between VINs and grain size are largely unknown. Moreover, there is no evidence to show any relationship between vacuolar invertase and seed size in rice, or how OsINV2, OsINV3, and INV3-INV2 influence grain size. Our results show that $I N V 3^{K O}$ causes small grain size (Figures 5 and 6), suggesting that OsINV3 positively regulates grain size by causing cell expansion resulting in an increase in grain length and grain-width. Genetic data showed that $I N V 2^{K O}$ did not cause any change in grain size by itself (Figures 8 and 9), but still plays important regulatory role in traits related to grain yield [42]. In our study, the double mutant $I N V 3^{K O} I N V 2^{K O}$ showed a grain size smaller than both $I N V 3^{K O}$ and $I N V 2^{K O}$ (Figure 9), suggesting that in the absence of OsINV3, it is possible to detect a role of OsINV2 in the regulation of grain size. As reported previously, the functions of OsINV2 were redundantly encoded in OsINV3 [42]. Our results show for the first time that OsINV2 regulates grain size in the absence of OsINV3. Based on these findings, we predicted that both OsINV3 and OsINV2 have effects on grain size.

\subsection{The Physiological Role of VINs in Regulating Grain Size}

Grain biomass accumulation is dependent on sucrose supply and hexose assimilation along the transport pathway from leaf to developing caryopsis $[25,27,28,32]$. Sugar transporters play pivotal 
roles in carbon partitioning by mediating long distance sucrose transport from source leaves to sink [25]. Since invertases are responsible for the degradation of sucrose [32], we evaluated the physiological roles of OsINV3 and OsINV2 in regulating grain size, including the enzyme activity and sugar composition in ZH11 and KO mutants. When compared to ZH11, the VIN activities of all the KO mutants were reduced in young panicles and at heading stage, whereas there was no difference in activity among the three types of invertases in the flag leaf at heading stage (Figure 10A). The sugar composition was consistently affected in all $\mathrm{KO}$ mutants, resulting in increased sucrose accumulation and reduced hexose (glucose and fructose) production (Figure 10B). Interestingly, the invertase activities (CIN, VIN, CWIN) and sugar composition were found to be markedly reduced in the $I N V 3^{K O} I N V 2^{K O}$ double mutant and the INV3 ${ }^{K O}$ single mutant when compared to ZH11. Starch is both an important caloric source and a molecule with a strong economic interest [55]. It is synthesized from hexose units derived from sucrose [52]. We also surveyed the starch contents of mature grains of KOs. There was no difference in the total starch content between ZH11 and KOs grains, while the amylose content decreased in grains from KOs (Figure S9). This indicated that sugar composition is affected in the single and double mutants, with increased sucrose accumulation and reduced hexose production as a consequence of changes in VIN, CIN activities, and starch constitution. The decreased invertase activity also resulted in reduced sucrose degradation, and grain biomass accumulation was blocked, resulting in smaller grain size.

\section{Materials and Methods}

\subsection{Plant Materials and Growth Conditions}

The sg2-1 and sg2-2 mutants (small grain size gene on Chromosome 2, sg2) were isolated from an ethyl methane sulfonate (EMS)-mutagenized population of indica cultivar Yixiang1B (wild type, WT). The Japonica cultivars included 02428, Dongjing (DJ), Hwayoung (HY) and Zhonghua11 (ZH11). Rice seeds used in this study were sourced from WT plants, $I N V 3^{K O}$ transgenic plants, $I N V 2^{K O}$ transgenic plants, OsINV3 overexpressing plants and T-DNA insertion mutants. Rice plants were planted in the fields at Wenjiang (Chengdu, China) in summer and Lingshui (Hainan, China) in winter. Seeds were sowed in fields and transplanted after 30 days. All materials were grown under natural environments and managed as breeding materials.

\subsection{Agronomic Traits Analysis}

For investigation of phenotypes, 15 randomly selected plants from a population were used for agronomic trait analysis at maturation stage. All phenotypic data were recorded from three biological replicates.

\subsection{Scanning Electron Microscopy (SEM)}

For SEM observation, spikelet hulls from WT, sg2-1, sg2-2, ZH11, and KO lines were collected before anthesis and fixed in $2.5 \%$ glutaraldehyde. The fixed samples were dehydrated in graded ethanol series. The samples were then dried in a critical-point drier, sputter-coated with gold, and observed by SEM (Inspect, FEI, USA) as previously described [56]. Cell length, cell width, and cell area were measured using Image J software.

\subsection{Genetic Analysis and Map-Based Cloning}

Mutmap [57] methodology was used for gene mapping. Briefly, four $F_{1}$ and four $F_{2}$ populations derived from the crosses WT $\times s g 2-1, s g 2-1 \times W T$, WT $\times s g 2-2$, and $s g 2-2 \times W T$ were used for genetic analysis. $\mathrm{F}_{2}$ populations derived from the crosses $02428 \times s g 2-1$ and $02428 \times s g 2-2$ were used for mapping of the mutant gene. DNA from $25 \mathrm{BC}_{1} \mathrm{~F}_{2}$ plants with small grain phenotype similar to sg2-1 was extracted and pooled in equal proportions, and subjected to whole-genome sequencing using Illumina Genome Analyzer IIx (Novogene, Beijing, China). Mixed DNA (5 $\mu \mathrm{g}$ ) was used for 
preparation of libraries for Illumina sequencing according to the protocol for the Paired-End DNA Sample Prep kit (Novogene, Beijing, China). The libraries were used for cluster generation on a flow cell and sequenced for 76 cycles on an Illumina Genome Analyzer IIx. DNA from WT was re-sequenced as a control. The SNPs/INDELs indexes were calculated as previously described [57]. Sequences of the PCR primers used for mapping and the amplified sg2-2 mutant genomic DNA sequence are given in Table S5.

\subsection{Isolation of the OsINV2 and OsINV3 T-DNA Insertion Mutants}

The T-DNA insertion mutants of OsINV3 (stock no. PFG-2D-30640) and OsINV2 (stock no. PFG-4A-50469) were obtained from the Korea Rice Mutant Database [58]. The inv2 and inv3 mutants were amplified using T-DNA primer R (5'-AACGCTGATCAATTCCACAG-3') and primers specific to OsINV2 and OsINV3 genes. The primers used for genotyping were, LP (5'-TTGGCTGAGTGGTGGTGTC-3') and RP (5'-GAGAGAGACACCAAATGATC-CATCC-3') for OsINV2; LP (5'-CTTCCCTCCAGGTACACCTTC-3') and RP (5'-GGAGGAGGAGAAGGGTTTTG-3') for OsINV3.

\subsection{Transgene Constructs}

For complementation of the $s g 2$ mutation, a plasmid containing the full-length wild-type cDNA and 2000 bp upstream of the putative translation start site (proINV3::INV3) was constructed by cloning into the binary vector pCAMBIA1300-YFP and then introduced into the sg2-1 mutant.

For overexpression, the 1986-bp CDS sequence of OsINV3 from the WT was cloned under the control of the CaMV35S promoter into the binary vector pCAMBIA2300-GFP and then introduced into ZH11.

To obtain KO mutants, two sgRNA target sites of OsINV3 (Figure 6A and Figure S6A) and one sgRNA target site of OsINV2 (Figure S6A) were designed, and the CRISPR/Cas9 plasmid construct was generated using the methods described previously [59].

The primer sequences for construction of the above-described vectors are listed in Table S6.

\subsection{Subcellular Localization of OsINV3 and OsINV2}

A plasmid containing full-length WT cDNA of OsINV3 was cloned into the vector pCAMBIA1300 to generate an N-terminal fusion with the yellow fluorescent protein (YFP) under control of the OsINV3 native promoter, resulting in pCAMBIA1300-INV3-YFP. Another plasmid containing the full-length CDS sequence of OsINV2 from ZH11 was cloned under the control of the CaMV35S promoter into the binary vector pCAMBIA2300-GFP, resulting in pCAMBIA2300-INV2-GFP. Rice protoplasts were isolated from the leaves of WT seedlings (7-15 days after germination with dark treatment, $30{ }^{\circ} \mathrm{C}$ ). pCAMBIA1300-INV3-YFP and pCAMBIA2300-INV2-GFP were introduced into the rice protoplasts using the method as described previously [60]. YFP or GFP fluorescence was detected using a confocal laser scanning microscope (Olympus FluoView FV1000, Japan).

\subsection{Invertase Activity Assays and Determination of Sugar and Starch Contents}

Young panicles (about $6 \sim 7 \mathrm{~cm}$ length panicles), heading stage and the flag leaf at heading stage were collected and assayed for invertase activity as described previously (VIN, CWIN, CIN) [40]. Samples for sugar content measurements were collected from young panicles (about $6 \sim 7 \mathrm{~cm}$ length panicles), heading stage and the flag leaf at heading stage and assayed as described previously [41]. The total starch content and amylose content in mature grains was measured using the Total Starch Assay Kit and the Amylose Assay Kit (https://www.cominbio.com), respectively, according to the manufacturer's instructions. 


\subsection{RNA Isolation and RT-qPCR}

Total RNA samples were obtained from the various plant tissues at different stages using the RNA Trizol (Invitrogen). One microgram of RNA was used to generate cDNA using a Revertase Transcription kit (Vazyme). The products were quantified using a real-time PCR detection system, following the manufacturer's instructions (SYBR Green Master Mix, Vazyme).

The PCR primers used are listed in Table S7. The rice Actin gene was used as an internal control.

\section{Conclusions}

The rice $s g 2$ mutant produces small grains. Map-based cloning revealed that the SG2 gene, encoding a vacuolar invertase, is an allele of OsINV3. We identified that OsINV3 is a positive regulator of grain size in rice while OsINV2 has no effect on grain size by itself. However, in the absence of OsINV3, it is possible to detect a role of OsINV2 in the regulation of grain size; the altered sugar composition, invertase activities and starch constitution in both single mutants ( $I N V 3^{K O}$ and $I N V 2^{K O}$ ) and double mutant $\left(I N V 3^{K O} I N V 2^{K O}\right)$ lead to altered sucrose import and degradation capacities, regulating grain size.

Supplementary Materials: Supplementary materials can be found at http://www.mdpi.com/1422-0067/21/6/2199/ s1.

Author Contributions: For research articles Data curation, X.H. and Y.T.; Formal analysis, X.D. and S.Y.; Funding acquisition, P.X. and Y.L.; Investigation, C.S.; Methodology, Z.L.; Project administration, H.Z.; Software, D.G.; Supervision, X.W.; Validation, H.Z. and X.C.; Visualization, Y.H. and W.L.; Writing-original draft, X.D.; Writing-review and editing, X.D. and X.W. All authors have read and agreed to the published version of the manuscript.

Funding: This research was funded by the National Key Research and Development Program of China (Grant No. 2016YFD0100406), The Key Breeding Research of Sichuan (Grant No. 2016NYZ0049), the Sichuan Science and Technology Program (Grant No. 2018JY0473), and the Sichuan Science and Technology Department (Grant No. 2019ZYD067).

Conflicts of Interest: The authors declare no conflict of interest.

\section{Abbreviations}

$\mathrm{KO}$

MAPK

PLATZ

CWINs

VINs

CINs

SEM

SNPS

PCR

YFP

PVCs

\author{
Knockout \\ Mitogen-Activated Protein Kinase \\ Plant AT-rich sequence- and zinc-binding \\ Cell Wall Invertases \\ Vacuolar Invertases \\ Cytoplasmic Invertases \\ Scanning Electron Microscopy \\ Single-Nucleotide Polymorphisms \\ Polymerase Chain Reaction \\ Yellow Fluorescent Protein \\ Prevacuolar compartments
}

\section{References}

1. Miura, K.; Ashikari, M.; Matsuoka, M. The role of QTLs in the breeding of high-yielding rice. Trends Plant Sci. 2011, 16, 319-326. [CrossRef]

2. Zuo, J.; Li, J. Molecular genetic dissection of quantitative trait loci regulating rice grain size. Annu. Rev. Genet. 2014, 48, 99-118. [CrossRef] [PubMed]

3. Zheng, J.; Zhang, Y.; Wang, C. Molecular functions of genes related to grain shape in rice. Breed. Sci. 2015, 65, 120-126. [CrossRef]

4. Li, N.; Li, Y. Signaling pathways of seed size control in plants. Curr. Opin. Plant Biol. 2016, 33, 23-32. [CrossRef] [PubMed] 
5. Li, N.; Xu, R.; Duan, P.; Li, Y. Control of grain size in rice. Plant Reprod. 2018, 31, 237-251. [CrossRef] [PubMed]

6. Li, N.; Xu, R.; Li, Y. Molecular Networks of Seed Size Control in Plants. Annu. Rev. Plant Biol. 2019, 70, 435-463. [CrossRef] [PubMed]

7. Song, X.J.; Huang, W.; Shi, M.; Zhu, M.Z.; Lin, H.X. A QTL for rice grain width and weight encodes a previously unknown RING-type E3 ubiquitin ligase. Nat. Genet. 2007, 39, 623-630. [CrossRef] [PubMed]

8. Li, J.; Chu, H.; Zhang, Y.; Mou, T.; Wu, C.; Zhang, Q.; Xu, J. The rice HGW gene encodes a ubiquitin-associated (UBA) domain protein that regulates heading date and grain weight. PLoS ONE 2012, 7, e34231. [CrossRef]

9. Hu, X.; Qian, Q.; Xu, T.; Zhang, Y.; Dong, G.; Gao, T.; Xie, Q.; Xue, Y. The U-box E3 ubiquitin ligase TUD1 functions with a heterotrimeric $\mathrm{G}$ alpha subunit to regulate Brassinosteroid-mediated growth in rice. PLoS Genet. 2013, 9, e1003391. [CrossRef]

10. Huang, K.; Wang, D.; Duan, P.; Zhang, B.; Xu, R.; Li, N.; Li, Y. WIDE AND THICK GRAIN 1, which encodes an otubain-like protease with deubiquitination activity, influences grain size and shape in rice. Plant J. 2017, 91, 849-860. [CrossRef]

11. Duan, P.; Rao, Y.; Zeng, D.; Yang, Y.; Xu, R.; Zhang, B.; Dong, G.; Qian, Q.; Li, Y. SMALL GRAIN 1, which encodes a mitogen-activated protein kinase kinase 4, influences grain size in rice. Plant J. 2014, 77, 547-557. [CrossRef] [PubMed]

12. Liu, S.; Hua, L.; Dong, S.; Chen, H.; Zhu, X.; Jiang, J.; Zhang, F.; Li, Y.; Fang, X.; Chen, F. OsMAPK6, a mitogen-activated protein kinase, influences rice grain size and biomass production. Plant J. 2015, 84, 672-681. [CrossRef] [PubMed]

13. Guo, T.; Chen, K.; Dong, N.Q.; Shi, C.L.; Ye, W.W.; Gao, J.P.; Shan, J.X.; Lin, H.X. GRAIN SIZE AND NUMBER1 Negatively Regulates the OsMKKK10-OsMKK4-OsMPK6 Cascade to Coordinate the Trade-off between Grain Number per Panicle and Grain Size in Rice. Plant Cell 2018, 30, 871-888. [CrossRef] [PubMed]

14. Xu, R.; Duan, P.; Yu, H.; Zhou, Z.; Zhang, B.; Wang, R.; Li, J.; Zhang, G.; Zhuang, S.; Lyu, J.; et al. Control of Grain Size and Weight by the OsMKKK10-OsMKK4-OsMAPK6 Signaling Pathway in Rice. Mol. Plant 2018, 11, 860-873. [CrossRef]

15. Xu, R.; Yu, H.; Wang, J.; Duan, P.; Zhang, B.; Li, J.; Li, Y.; Xu, J.; Lyu, J.; Li, N.; et al. A mitogen-activated protein kinase phosphatase influences grain size and weight in rice. Plant J. 2018, 95, 937-946. [CrossRef]

16. Urano, D.; Jones, A.M. Heterotrimeric G protein-coupled signaling in plants. Annu. Rev. Plant Biol. 2014, 65, 365-384. [CrossRef]

17. Sun, S.; Wang, L.; Mao, H.; Shao, L.; Li, X.; Xiao, J.; Ouyang, Y.; Zhang, Q. A G-protein pathway determines grain size in rice. Nat. Commun. 2018, 9, 851. [CrossRef]

18. Wang, M.; Lu, X.; Xu, G.; Yin, X.; Cui, Y.; Huang, L.; Rocha, P.S.; Xia, X. OsSGL, a novel pleiotropic stress-related gene enhances grain length and yield in rice. Sci. Rep. 2016, 6, 38157. [CrossRef]

19. Cui, Y.; Wang, M.; Zhou, H.; Li, M.; Huang, L.; Yin, X.; Zhao, G.; Lin, F.; Xia, X.; Xu, G. OsSGL, a Novel DUF1645 Domain-Containing Protein, Confers Enhanced Drought Tolerance in Transgenic Rice and Arabidopsis. Front. Plant Sci. 2016, 7, 2001. [CrossRef]

20. Jin, J.; Hua, L.; Zhu, Z.; Tan, L.; Zhao, X.; Zhang, W.; Liu, F.; Fu, Y.; Cai, H.; Sun, X.; et al. GAD1 Encodes a Secreted Peptide That Regulates Grain Number, Grain Length, and Awn Development in Rice Domestication. Plant Cell 2016, 28, 2453-2463. [CrossRef]

21. Kitagawa, K.; Kurinami, S.; Oki, K.; Abe, Y.; Ando, T.; Kono, I.; Yano, M.; Kitano, H.; Iwasaki, Y. A novel kinesin 13 protein regulating rice seed length. Plant Cell Physiol. 2010, 51, 1315-1329. [CrossRef] [PubMed]

22. Li, J.; Jiang, J.; Qian, Q.; Xu, Y.; Zhang, C.; Xiao, J.; Du, C.; Luo, W.; Zou, G.; Chen, M.; et al. Mutation of rice BC12/GDD1, which encodes a kinesin-like protein that binds to a GA biosynthesis gene promoter, leads to dwarfism with impaired cell elongation. Plant Cell 2011, 23, 628-640. [CrossRef] [PubMed]

23. Ji, X.; Du, Y.; Li, F.; Sun, H.; Zhang, J.; Li, J.; Peng, T.; Xin, Z.; Zhao, Q. The basic helix-loop-helix transcription factor, OsPIL15 regulates grain size via directly targeting a purine permease gene OsPUP7 in rice. Plant Biotechnol. J. 2019, 17, 1-12. [CrossRef] [PubMed]

24. Wang, A.; Hou, Q.; Si, L.; Huang, X.; Luo, J.; Lu, D.; Zhu, J.; Shangguan, Y.; Miao, J.; Xie, Y.; et al. The PLATZ transcription factor GL6 affects grain length and number in rice. Plant Physiol. 2019, 180, 2077-2090. [CrossRef] [PubMed]

25. Koch, K. Sucrose metabolism: Regulatory mechanisms and pivotal roles in sugar sensing and plant development. Curr. Opin. Plant Biol. 2004, 7, 235-246. [CrossRef] 
26. Rolland, F.; Baena-Gonzalez, E.; Sheen, J. Sugar sensing and signaling in plants: Conserved and novel mechanisms. Annu. Rev. Plant Biol. 2006, 57, 675-709. [CrossRef]

27. Ruan, Y.L. Sucrose metabolism: Gateway to diverse carbon use and sugar signaling. Annu. Rev. Plant Biol. 2014, 65, 33-67. [CrossRef]

28. Wan, H.; Wu, L.; Yang, Y.; Zhou, G.; Ruan, Y.L. Evolution of Sucrose Metabolism: The Dichotomy of Invertases and Beyond. Trends Plant Sci. 2018, 23, 163-177. [CrossRef]

29. Roitsch, T.; Gonzalez, M.C. Function and regulation of plant invertases: Sweet sensations. Trends Plant Sci. 2004, 9, 606-613. [CrossRef]

30. Wang, E.; Wang, J.; Zhu, X.; Hao, W.; Wang, L.; Li, Q.; Zhang, L.; He, W.; Lu, B.; Lin, H.; et al. Control of rice grain-filling and yield by a gene with a potential signature of domestication. Nat. Genet. 2008, 40, 1370-1374. [CrossRef]

31. Li, B.; Liu, H.; Zhang, Y.; Kang, T.; Zhang, L.; Tong, J.; Xiao, L.; Zhang, H. Constitutive expression of cell wall invertase genes increases grain yield and starch content in maize. Plant Biotechnol. J. 2013, 11, 1080-1091. [CrossRef] [PubMed]

32. Li, J.; Wu, L.; Foster, R.; Ruan, Y.L. Molecular regulation of sucrose catabolism and sugar transport for development, defence and phloem function. J. Integr. Plant Biol. 2017, 59, 322-335. [CrossRef] [PubMed]

33. Sergeeva, L.I.; Keurentjes, J.J.; Bentsink, L.; Vonk, J.; van der Plas, L.H.; Koornneef, M.; Vreugdenhil, D. Vacuolar invertase regulates elongation of Arabidopsis thaliana roots as revealed by QTL and mutant analysis. Proc. Natl. Acad. Sci. USA 2006, 103, 2994-2999. [CrossRef] [PubMed]

34. Ogawa, A.; Ando, F.; Toyofuku, K.; Kawashima, C. Sucrose Metabolism for the Development of Seminal Root in Maize Seedlings. Plant Prod. Sci. 2009, 12, 9-16. [CrossRef]

35. Wang, L.; Li, X.R.; Lian, H.; Ni, D.A.; He, Y.K.; Chen, X.Y.; Ruan, Y.L. Evidence that high activity of vacuolar invertase is required for cotton fiber and Arabidopsis root elongation through osmotic dependent and independent pathways, respectively. Plant Physiol. 2010, 154, 744-756. [CrossRef]

36. Wiberley-Bradford, A.E.; Busse, J.S.; Jiang, J.; Bethke, P.C. Sugar metabolism, chip color, invertase activity, and gene expression during long-term cold storage of potato (Solanum tuberosum) tubers from wild-type and vacuolar invertase silencing lines of Katahdin. BMC Res. Notes 2014, 7, 801. [CrossRef]

37. Wiberley-Bradford, A.E.; Bethke, P.C. Suppression of the vacuolar invertase gene delays senescent sweetening in chipping potatoes. J. Sci. Food Agric. 2018, 98, 354-360. [CrossRef]

38. Zhu, X.; Richael, C.; Chamberlain, P.; Busse, J.S.; Bussan, A.J.; Jiang, J.; Bethke, P.C. Vacuolar invertase gene silencing in potato (Solanum tuberosum L.) improves processing quality by decreasing the frequency of sugar-end defects. PLOS ONE 2014, 9, e93381. [CrossRef]

39. Ji, X.; Van den Ende, W.; Van Laere, A.; Cheng, S.; Bennett, J. Structure, evolution, and expression of the two invertase gene families of rice. J. Mol. Evol. 2005, 60, 615-634. [CrossRef]

40. Morey, S.R.; Hirose, T.; Hashida, Y.; Miyao, A.; Hirochika, H.; Ohsugi, R.; Yamagishi, J.; Aoki, N. Genetic Evidence for the Role of a Rice Vacuolar Invertase as a Molecular Sink Strength Determinant. Rice 2018, 11, 6. [CrossRef]

41. Xu, X.; Ren, Y.; Wang, C.; Zhang, H.; Wang, F.; Chen, J.; Liu, X.; Zheng, T.; Cai, M.; Zeng, Z.; et al. OsVIN2 encodes a vacuolar acid invertase that affects grain size by altering sugar metabolism in rice. Plant Cell Rep. 2019, 38, 10-1007. [CrossRef] [PubMed]

42. Morey, S.R.; Hirose, T.; Hashida, Y.; Miyao, A.; Hirochika, H.; Ohsugi, R.; Yamagishi, J.; Aoki, N. Characterisation of a rice vacuolar invertase isoform, OsINV2, for growth and yield-related traits. Funct. Plant Biol. 2019, 46, 777-785. [CrossRef] [PubMed]

43. Hu, J.; Wang, Y.; Fang, Y.; Zeng, L.; Xu, J.; Yu, H.; Shi, Z.; Pan, J.; Zhang, D.; Kang, S.; et al. A Rare Allele of GS2 Enhances Grain Size and Grain Yield in Rice. Mol. Plant 2015, 8, 1455-1465. [CrossRef] [PubMed]

44. Wang, Y.; Xiong, G.; Hu, J.; Jiang, L.; Yu, H.; Xu, J.; Fang, Y.; Zeng, L.; Xu, E.; Xu, J.; et al. Copy number variation at the GL7 locus contributes to grain size diversity in rice. Nat. Genet. 2015, 47, 944-948. [CrossRef] [PubMed]

45. Segami, S.; Kono, I.; Ando, T.; Yano, M.; Kitano, H.; Miura, K.; Iwasaki, Y. Small and round seed 5 gene encodes alpha-tubulin regulating seed cell elongation in rice. Rice 2012, 5, 4. [CrossRef] [PubMed]

46. Fang, N.; Xu, R.; Huang, L.; Zhang, B.; Duan, P.; Li, N.; Luo, Y.; Li, Y. SMALL GRAIN 11Controls Grain Size, Grain Number and Grain Yield in Rice. Rice 2016, 9, 64. [CrossRef] 
47. Li, Y.; Fan, C.; Xing, Y.; Jiang, Y.; Luo, L.; Sun, L.; Shao, D.; Xu, C.; Li, X.; Xiao, J. Natural variation in GS5 plays an important role in regulating grain size and yield in rice. Nat. Genet. 2011, 43, 1266-1270. [CrossRef]

48. Fan, C.; Xing, Y.; Mao, H.; Lu, T.; Han, B.; Xu, C.; Li, X.; Zhang, Q. GS3, a major QTL for grain length and weight and minor QTL for grain width and thickness in rice, encodes a putative transmembrane protein. Theor. Appl. Genet. 2006, 112, 1164-1171. [CrossRef]

49. Qi, P.; Lin, Y.S.; Song, X.J.; Shen, J.B.; Huang, W.; Shan, J.X.; Zhu, M.Z.; Jiang, L.; Gao, J.; Lin, H. The novel quantitative trait locus GL3.1 controls rice grain size and yield by regulating Cyclin-T1;3. Cell Res. 2012, 22, 1666-1680. [CrossRef]

50. Tamura, K.; Shimada, T.; Ono, E.; Tanaka, Y.; Nagatani, A.; Higashi, S.-i.; Watanabe, M.; Nishimura, M.; Hara-Nishimura, I. Why green fluorescent fusion proteins have not been observed in the vacuoles of higher plants. Plant J. 2003, 35, 545-555. [CrossRef]

51. Jung, C.; Lee, G.-J.; Jang, M.; Lee, M.; Lee, J.; Kang, H.; Sohn, E.J.; Hwang, I. Identification of Sorting Motifs of At $\beta$ Fruct 4 for Trafficking from the ER to the Vacuole Through the Golgi and PVC. Traffic 2011, 12, 1774-1792. [CrossRef] [PubMed]

52. Hannah, L.C.; James, M. The complexities of starch biosynthesis in cereal endosperms. Curr. Opin. Biotechnol. 2008, 19, 160-165. [CrossRef] [PubMed]

53. Andersen, M.N.; Asch, F.; Wu, Y.; Jensen, C.R.; Naested, H.; Mogensen, V.O.; Koch, K.E. Soluble invertase expression is an early target of drought stress during the critical, abortion-sensitive phase of young ovary development in maize. Plant. Physiol. 2002, 130, 591-604. [CrossRef] [PubMed]

54. Chopra, J.; Kaur, N.; Gupta, A.K. Changes in the activities of carbon metabolizing enzymes with pod development in lentil (Lens culinaris L.). Acta Physiol. Plant. 2003, 25, 185-191. [CrossRef]

55. James, M.G.; Denyer, K.; Myers, A.M. Starch synthesis in the cereal endosperm. Curr. Opin. Plant Biol. 2003, 6, 215-222. [CrossRef]

56. Zhao, D.S.; Li, Q.F.; Zhang, C.Q.; Zhang, C.; Yang, Q.Q.; Pan, L.X.; Ren, X.Y.; Lu, J.; Gu, M.H.; Liu, Q.Q. GS9 acts as a transcriptional activator to regulate rice grain shape and appearance quality. Nat. Commun. 2018, 9 , 1240. [CrossRef]

57. Abe, A.; Kosugi, S.; Yoshida, K.; Natsume, S.; Takagi, H.; Kanzaki, H.; Matsumura, H.; Yoshida, K.; Mitsuoka, C.; Tamiru, M.; et al. Genome sequencing reveals agronomically important loci in rice using MutMap. Nat. Biotechnol. 2012, 30, 174-178. [CrossRef]

58. Jeong, D.H.; An, S.; Park, S.; Kang, H.G.; Park, G.G.; Kim, S.R.; Sim, J.; Kim, Y.O.; Kim, M.K.; Kim, S.R.; et al. Generation of a flanking sequence-tag database for activation-tagging lines in japonica rice. Plant. J. 2006, 45, 123-132. [CrossRef]

59. Ma, X.; Zhang, Q.; Zhu, Q.; Liu, W.; Chen, Y.; Qiu, R.; Wang, B.; Yang, Z.; Li, H.; Lin, Y.; et al. A Robust CRISPR/Cas9 System for Convenient, High-Efficiency Multiplex Genome Editing in Monocot and Dicot Plants. Mol. Plant. 2015, 8, 1274-1284. [CrossRef]

60. Wang, S.; Wu, K.; Qian, Q.; Liu, Q.; Li, Q.; Pan, Y.; Ye, Y.; Liu, X.; Wang, J.; Zhang, J.; et al. Non-canonical regulation of SPL transcription factors by a human OTUB1-like deubiquitinase defines a new plant type rice associated with higher grain yield. Cell Res. 2017, 27, 1142-1156. [CrossRef]

(C) 2020 by the authors. Licensee MDPI, Basel, Switzerland. This article is an open access article distributed under the terms and conditions of the Creative Commons Attribution (CC BY) license (http://creativecommons.org/licenses/by/4.0/). 